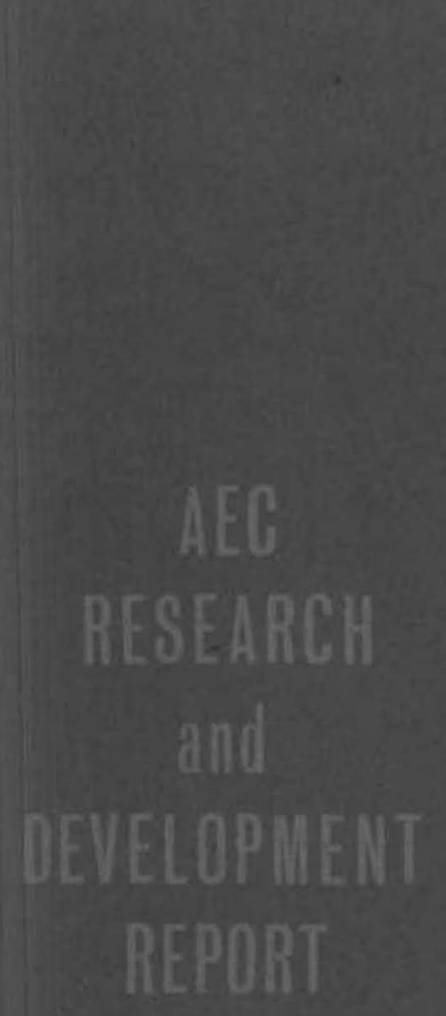

B NWL -217

\title{
SUBISOKINETIC SAMPLING OF PARTICLES \\ IN AN AIR STREAM
}

G. A. Sehmel

March 1, 1966
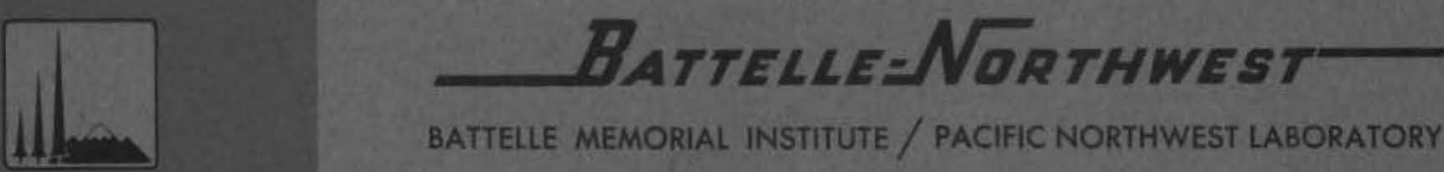

BATTELLE MEMORIAL INSTITUTE / PACIFIC NORTHWEST LABORATORY 


\section{LEGAL NOTICE}

This report was prepared as an account of Government sponsored work. Neither the United States, nor the Commission, nor any person acting on behalf of the Commissioni

A. Makes any warranty or representation, expressed or implied, with respect to the occuracy, completeness, or usefulness of the information contained in this report, or that the use of any information, apparatus, method, or process disclosed in this report may not infringe privately owned rights; or

B. Assumes any liabilities with respect to the use of, or for damages resulting from the use of any information, opporatus, method, or process disclosed in this report.

As used in the above, "persan acting on behalf of the Commission" includes any employee or contractor of the Commission, or employee of such contractor, to the extent that such employee or contractor of the Commisston, or employee of such contractor prepares, disseminates, or provides occess to, any information pursuant to his employment or controct with the Commission, or his employment with such contractor.

\section{PACIFIC NORTHWEST LABORATORY}

RICHLAND, WASHINGTON

operated by

BATTELIE MEMORIAL INSTITUTE

for the

UNITED STATES ATOMIC ENERGY COMMISSION UNDER CONTRACT AT(45-1)-1830 


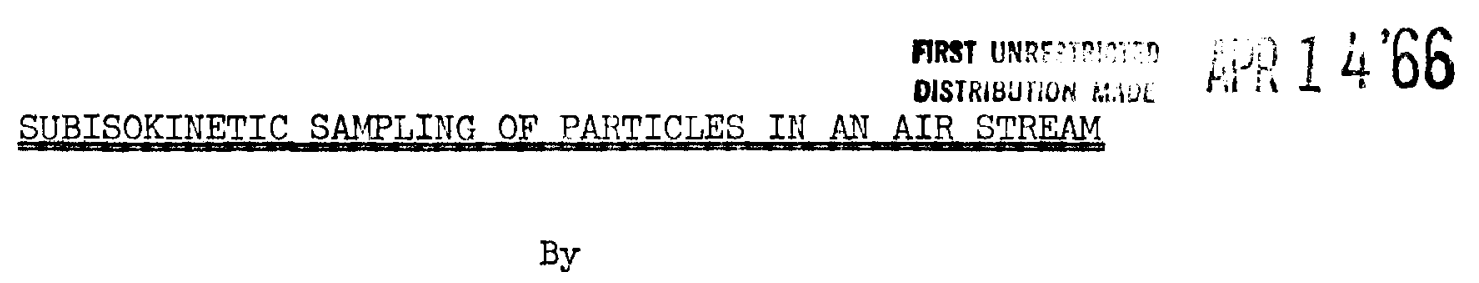

G. A. Sehmel

Particulate \& Gaseous Waste Research
Earth Sciences
ENVIRONMENTAL \& RADIOLOGICAL SCIENCES

March 1, 1966

BATTELLE-NORTHWEST

Pacific Northwest Laboratory

Richland, Washington

Work performed under Contract No. AT(45-1)-1830 between the Atomic Energy Commission and Battelle Memorial Institute 


\section{TABLE OF CONTENTS}

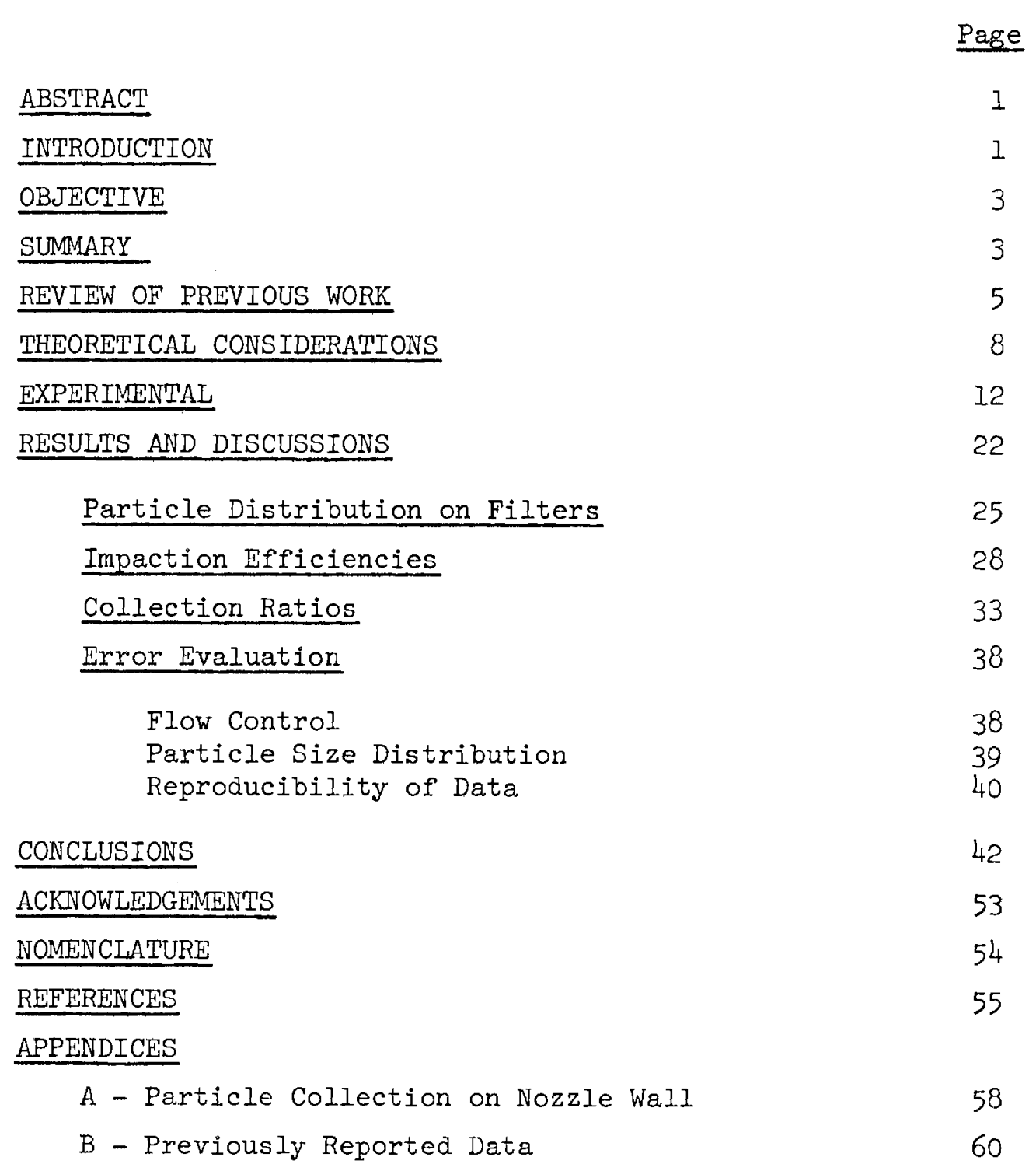


$\star$

LIST OF TABLES

Page

Table I -- Summary of Operating Conditions For

23 Collection Ratio Determinations

Table II -- Representative Particle Collection

26 on Retaining, Ring 


\section{LIST OF FIGURES}

Figure

$\underline{\text { Page }}$

No.

Effect of Particle Inertia on Various Types of Anisokinetic

Aerosol Sampling

2

Assembled and Disassembled Filter Holder

Least Squares Fit of the Drag Coefficients Summarized

by Fuchs[11] for Spherical Particles

4 Magnitude of Increased Stop Distance Caused by Neglecting Deviations from Stokes Law Behavior for Spherical Particles

Typical Number Distributions for Zinc Sulfide

Typical Weight Distributions for Zinc Sulfide

Photograph of Wind Tunnel

Schematic Diagram of Wind Tunnel

Nozzle and Filter Holder Assemblies

20

Calculated and Experimental Size Distributions

24

Particle Collection Patterns as a Function of Windspeed and Sampling Ratio

Effect of Velocities on Visually Determined Particle Distributions on Filter for Particle Size Distributions

13 Inertial Deposition of Particles on Filters as a Function of Windspeed

14 Adjusted Stokes' Number as a Function of Particle Size and Initial Velocity for Spherical Particles Sampling Ratio $\left(U / U_{O}\right.$ ) for a $2.7 \mathrm{mph}$ Windspeed

16 Collection Ratio for each Particle Size as a Function of Sampling Ratio $\left(\mathrm{U} / \mathrm{U}_{\mathrm{O}}\right.$ ) for a $9 \mathrm{mph}$ Windspeed

17 Collection Ratio for each Particle Size as a Function of Sampling Ratio $\left(U / U_{O}\right)$ for a $16.5 \mathrm{mph}$ Windspeed

Collection Radio for each Particle Size as a Function of Sampling Ratio $\left(U / U_{O}\right)$ for a $30 \mathrm{mph}$ Windspeed

Concentration Ratios for a $2.7 \mathrm{mph}$ Windspeed

Concentration Ratios for a $5.4 \mathrm{mph}$ Windspeed

Concentration Ratios for a $9.0 \mathrm{mph}$ Windspeed

44

Concentration Ratios for a $16.5 \mathrm{mph}$ Windspeed 
List of Figures (Continued)

Figure

No.

$\underline{\text { Page }}$

26 Concentration Ratios for Type 2330 Particles

27 Collection of Particles on Nozzles At Isokinetic Entrance

59

28 Velocities

61 Sampling Ratio $\left(U / U_{O}\right.$ ) for a $3.7 \mathrm{mph}$ Windspeed 
The errors associated with subisokinetically sampling aerosols from an air stream were determined for one filter holder geometry with a $41 \mathrm{~mm}$ diameter filter area exposed. Sampling velocities ranged from 0.008 of isokinetic to isokinetic for airspeeds from 2.7 to $30 \mathrm{mph}$. Zine sulfide aerosol particles with diameters 3 to 25 microns were studied. Microscopic techniques were used to evaluate the number of particles on the filters. In order to determine sampling errors as a function of particle size, least squares techniques were used to determine truncated particle size distributions. To correlate the data the collection efficiencies were approximated by an expression which includes the impaction efficiency as a function of particle size for each windspeed. From these, overall sampling errors were calculated for several particle size distributions of principal use with the filter geometry. overall sampling error correction factors were as high as 58 .

INTRODUCTION

A truly representative and accurate aerosol sample of an aerosol-laden air stream in general will be obtained on a filter only if the sample air is withdrawn parallel to the stream flow, only if the air velocity through the filter is identical to the undisturbed air stream velocity at the sampling point, and only if edge effects do not disturb the aerodynamic stream lines of the approaching air. Sampling under these conditions is termed isokinetic. In practice these requirements are seldom, if ever, absolutely achieved. If the sampled air is turbulent, a steady sampling flow can never be truly isokinetic due to the fluctuations in the turbulent flow.

Three general sampling conditions can exist which illustrate the effect of the aerosol particle's inertia on the collection on the filter. These are illustrated schematically in Figure 1 in which the air stream lines are indicated by solid lines and deviations of particle movement from the stream lines are indicated by the dashed lines. The particle motion is seen to deviate from the stream line because of inertia. Impaction on discs exists as the limit to subisokinetic sampling. 


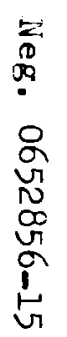

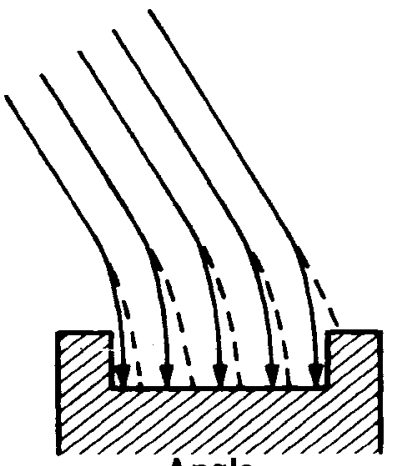

Angle

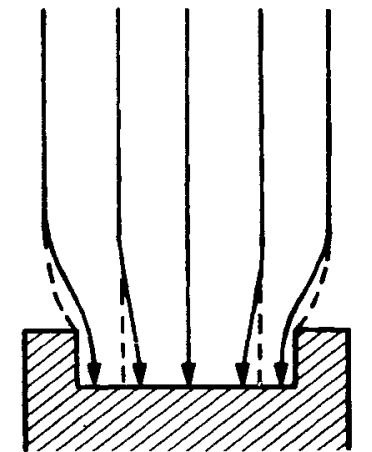

Superisokinetic

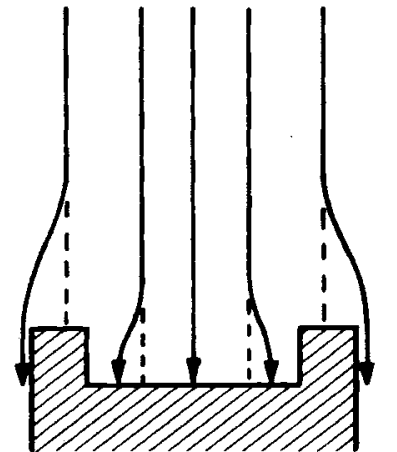

Subisokinetic

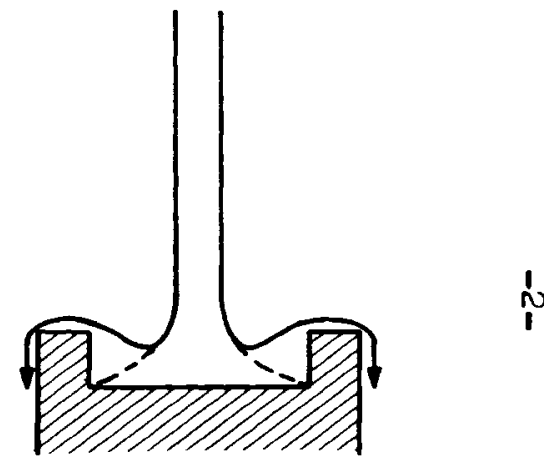

Impaction 
In order for one to properly evaluate the true air stream concentration from particulates collected upon filters during subisokinetic sampling, factors are necessary to correct for the effects of particle inertia upon filter collection. These correction factors can be determined from a theoretical evaluation of the force balance on each particle and a knowledge of the vector velocity profile of the air in front of the filter. The velocity profile can be estimated for viscous or potential flow around simple body shapes such as cylinders or spheres. However, for cases in which flow goes through the collecting body, sufficiently accurate velocity profiles would be difficult to obtain. Thus, an experimental method for correction factor determination is used. This is a direct evaluation of the number of each size particle collected upon a subisokinetically sampled filter. The number of particles collected on the subisokinetically sampled filter is compared witr the number of same size particle collected on a filter through which an isokinetic flow rate exists. Since both the subisokinetic and isokinetic filters sample fram air of a uniform velocity and particle concentration, the ratio of the particle collection for the two filters is an indication of the sampling correction factor. The correction factors are a function of particle size, particle density, windspeed, turbulence, electrical charges, the ratio of subisokinetic to isokinetic flow rates, and the filter holder geometry.

OBJECTIVE

In the present study, sampling correction factors were to be determined for use with the filter holder ${ }^{[1,2]}$ shown in Figure 2。 The correction factors were to be applicable to the particles actually collected on the membrane filter and not applicable to the particles collected by impaction upon the filter holder. of principal interest were correction factors for zinc sulfide particles between 3 and 25 microns in diameter, windspeeds between 3 and $30 \mathrm{mph}$, and sampling rates of $0.3,0.45,2.0$, and $1, n \mathrm{fm}$. Since an isokinetic flow rate at $30 \mathrm{mph}$ would correspond to $38 \mathrm{cfm}$ through the filter, these samping rates corresponded to as low as 0.008 of isokinetic flow. Due to these low sampling rate ratios, impaction without flow through the filter was studied as the lower limit of subisokinetic sampling.

SUMMARY

Sampling error correction factors for zinc sulfide particles 3 to 20 microns in diameter were determined experimentally from a series of two simultaneously 


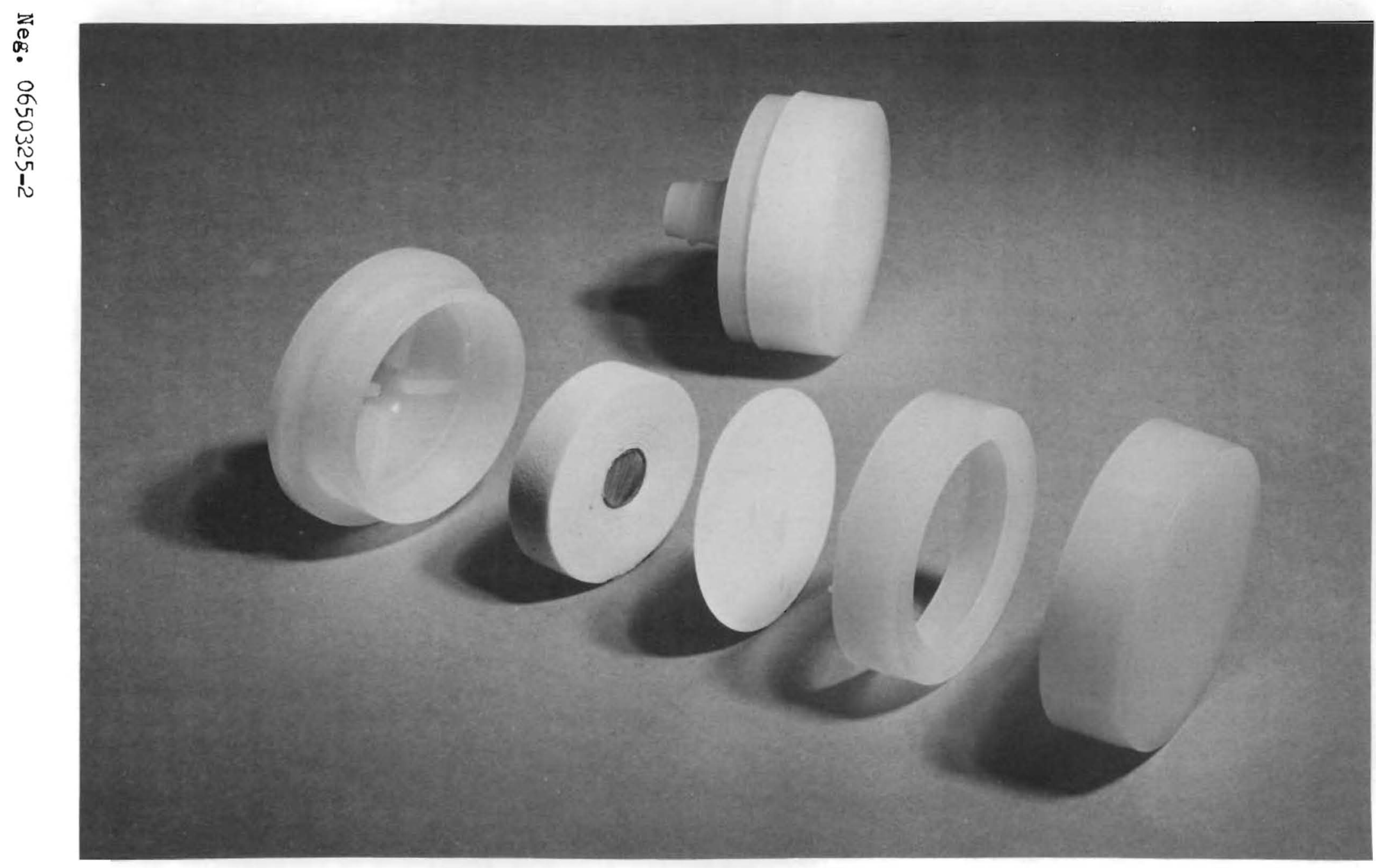

$f$

FIGURE 2

Assembled and Disassembled Filter Holdèr. 
collected air samples in a recirculating tunnel. One sample was collected on a 4l-mm membrane filter through which an isokinetic air flor was drawn. The other was collected on an identical filter through which a known subisokinetic flow was maintained. The filters were inspected microscopically to determine the number of each size particle collected on the two filters. The range of sampling flows was from zero (impaction) to 0.8 isokinetic over a windspeed ranging from 2.7 to 30 miles per hour.

The efficiency of impaction which represents the extreme case of subisokinetic flow, was correlated with the Stokes? Number (particle stop distance divided by the filter radius). The impaction data thus obtained were used in confunction with a simple mathematical model to help establish the sampling correction at subisokinetic flows.

Results of this study are presented as a series of curves showing the best estimates of the ratio of apparent particle concentrations to the true concentration as a function of the ratio of face velocity through the filter to windspeed, particle size, and the windspeed.

The usual problems faced in particle sampling and analysis were present in this study, particularly those of microscopic sizing and counting. Additional uncertainties were introduced due to the rather complex geometry of the filter holder. A sizeable experimental error is manifest in many of the results reported, yet the data, nevertheless, represent the only data available for the extreme ranges of subisokinetic flows considered. Sources of error and estimates of their magnitude are presented.

\section{REVIEW OF PREVIOUS WORK}

Stream lines of particles entering orifices at isokinetic flow and subisokinetic flow have been pictured by May.[3] For sampling at half windspeed the stream lines start to diverge around the collector at about one collector diameter upstream.

Impaction on the filter as the lower limit to subisokinetic sampling is equivalent to impaction upon a flat disc. For the disc the greatest concentration of particles would be at the center and the concentration would decrease in the radial direction. To picture the flow, Sell ${ }^{[4]}$ has shown the stream lines approaching a disc and from these determined the velocity profiles. Knowledge of the velocity profiles allowed calculation of the impaction efficiency as a function of the Stokes ${ }^{8}$ Number which is the ratio of the particle stop- 
distance to the disc radius. In addition Sell shows stream lines for particles entering and impacting into a cylindrical cup. This configuration would approximate the stream lines expected for impaction on the filter holder used in this study with its cylindrical filter retaining ring. Impaction on discs has been experimentally determined by Yeomans [5] for D.D.T. particles of mass median diameters between 9 and 34 microns for disc diameters between 1.6 and 6 Inches, and wind speeds from 2 to $8 \mathrm{mph}$. The true air stream concentrations were calculated from the total number of particles introduced into a wind tunnel. From these concentrations impaction efficiencies calculated by Yeomans were determined which were usually between 0.1 to 1.0 of that predicted by sell.

For subisokinetic flows at finite rates, several investigators have determined sampling correction factors. The correction factors have not been generally correlated, but correlation attempts have used three principal factors. These are Stokes ${ }^{\natural}$ Number, Stk, the ratio, U/UO, of subisokinetic flow to isokinetic flow, and \& hypothetical annular area of air from which particles cross stream lines and impact on the filter.

If the particle diameters are so large that the particle motion does not deviate from a straight line when approaching a filter, the number of particles collected on a subisokinetic filter would be independent of sampling rates. This case was approached by Hemeon and Haines ${ }^{[6]}$ who usea particles up to 500 microns in diameter.

For smaller sized particles and sampling rates greater than 0.2 of isokinetic. Badzioch ${ }^{[7]}$ determined concentration ratios for particle sizes between 20 microns and 30 microns in diameter. For the determinations, subisokinetic and isokinetic samples were alternately obtained through a single tube extending into a recirculating wind tunnel. Subisokinetic concentration ratios as high as four were obtained. The results were interpreted in terms of calculated distances up-stream of the sample tube at which the air motion was disturbed by the presence of the sample tube. Both Badzioch and Watson [8] use the concept that all particles are collected from the air passing through the filter and that a fraction of the particles is collected by inertia from the air diverted around the filter at subisokinetic flow. In Watson's work, samples were sim. ultaneously collected for subisokinetic and isokinetic flows into impingers containing distilled water for spore sizes of 4 and 32 microns diameter. Watson also shows the unpublished work of Mayhood and Langstroth. The largest concentration ratio shown for subisokinetic flow is about 1.5 for 37 micron diameter particles. 
The results of theoretical calculations of the errors associated with anisokinetic sampling have been presented by Vitols [9] who approximated the air motion in front of a nozzle by a frictionless ideal fluid and determined the particle trajectories by solvine the equations of motion for the particle. Assumptions included a sampling nozzle of negligible thickness, inertia as the predominant mechanism of collection, and no gravitational force acted on the particles. Reasonably good agreement was obtained in comparison with the data of Badzioch ${ }^{[7]}$ and Hemeon and Haines. [6]

A further aspect of anisokinetic sampling is the effect of non-alignment of the sample collector and the windstream. Under non-alignment conditions inertia will tend to cause the particles to bypass the collector. Watson shows Mayhood and Langstroth's data for isokinetic flow rates with correction factors for the inlet tube aligned to the windstream at various angles up to $180^{\circ}$ for 4, 12, and 37 micron diameter particles. Illustrative of the effects is that less than 50 per cent of 12-micron diameter particles will be collected at a $90^{\circ}$ angle to the air flow direction. For various inlet geometries with the filters facing upwards in a horizontal air stream, Duffee, Schulz, and Ungar [10] have considered various sampling rates for 6 and 12 micron diameter particles.

Concentration ratio correction factors have not been determined for subisokinetic to isokinetic flow rate ratios below 0.2 which are considered in the present investigation. Additional sampling error studies have been performed, but in the main the results cannot be identified with a particular particle size or material. These are listed below. In addition, since impaction, diffusion, and electrical effects can affect the particle collection, references for these mechanisms are included in the list showing supplemental background literature.

Background Literature

$\begin{array}{ll}\text { Anisokinetic Sampling } & 11,12,13,14,15 \\ \text { Sumriaries } & 16,17,18 \\ \quad \text { Experimental } & 19,20,21,22,23,24,25 \\ \text { Diffusion and Electrica] Effects } & 26,27 \\ \text { Impaction Theory } & 28,29,30,31,32,33\end{array}$


THEORETICAL CONSIDERATIONS

Several mechanisms can cause particles to collect on a filter facing into a horizontally moving aerosol laden air stream. If the sampling rate through the filter is subisokinetic, some of the air approaching the filter is diverted around the filter. This rate of diverted annular volume of air corresponds to the difference in the sampling rate and an isokinetic sampling rate. Particles near the inner boundary of this annular volume may have sufficient inertia to continue in a nearly straight line so as to cross the diverging air and impact on the filter surface. If the sampling rate is zero or very low, electrostatic attraction, diffusion to the filter surface, and the level of turbulence may also become significant. Only the aerodynamic effects are to be considered. Analytical expressions may be derived which express the filter collection as a function of the diverted air and the impaction efficiency at zero flow through the filter.

For subisokinetic sampling, the particles collected on a filter may be thought of as coming from two sources of particles in the cylinder of air approaching the filter. The two portions correspond to the air drawn through the filter and the air diverted around the filter. All the particles initially in the air drawn through the filter will be collected on the filter. In addition, a fraction, $\varepsilon$, of the particles in the diverted air will be collected on the filter. This fraction is a function of the subisokinetic to isokinetic flow ratio, windspeed, level of air turbulence, particle size, filter holder geometry, filter alignment, and electrical charge effects between particles and between particles and the filter. The model would predict that the number of particles, $\mathbb{N}$, collected on a filter through which a subisokinetic flow is drawn could be expressed in terms of the number of particles, No, collected on a filter through which a truly isokinetic flow is drawn. The relationship is

$$
\frac{\mathrm{N}}{\mathrm{N}_{0}}=\frac{\mathrm{U}}{\mathrm{U}_{0}}+\varepsilon\left(I-\frac{\mathrm{U}}{\mathrm{U}_{0}}\right)
$$

where $U$ is the subisokinetic flow rate and $U_{O}$ is the isokinetic flow. The term, $U / U_{0}$, expresses the fraction of particles within the air drawn through the filter and the term, $\left(I-U / U_{0}\right)$, expresses the fraction of air which is diverted around the filter.

Since Equation $I$ is completely general, the problem in subisokinetic sampling is that the relationship for predicting $\varepsilon$ is unknown. Consider the values 
of $\varepsilon$ for impaction and finite flow rates. For impaction, the values of $\varepsilon$ are influenced by a region of "stationary" air ${ }^{[7]}$ forming a cushion of air in front of the filter. For finite flow rates, the filter holder is equivalent to a ring-like deflector in which air is drawn through the filter or deflected around the retaining ring. Thus, equivalency of $\varepsilon$ for impaction and for finite flow rates may be a fortunate circumstance.

Considering only inertial effects, the magnitude of $\varepsilon$ approaches unity for particles of the order of 100-500 microns in diameter. [6] The value of $\varepsilon$ is related to the subisokinetic concentration ratio which is defined by the experimentally determined ratio

$$
\frac{\mathrm{C}}{\mathrm{C}_{\mathrm{O}}}=\frac{\mathrm{N}}{\mathrm{N}_{\mathrm{O}}} \frac{\mathrm{U}_{0}}{\mathrm{U}}
$$

in which $\mathrm{C}$ is the calculated apparent air stream concentration and $\mathrm{C}_{O}$ is the true concentration. If $\varepsilon$ equals zero, particles would follow the motion of the air and Equation 2 would then show that $C$ and $C_{0}$ are equivalent. If $E$ is greater than zero, the apparent air stream concentration is greater than the true concentration. In application, the concentration ratio is the value by which the calculated air stream concentration must be divided in order to obtain the true air concentration.

The value of $\varepsilon$ can be evaluated for "pure" impaction on the filter. In this case, $U / U_{0}=0$ and Equation $I$ reduces to

$$
\frac{\mathrm{N}}{\mathrm{N}_{\mathrm{O}}}=\varepsilon_{\text {Impaction }}
$$

Impaction will be considered in more detail since a theoretical correlating parameter exists for equality of $\varepsilon$ between flow conditions. This parameter is the Stokes'Number. The Stokes'Number is defined by

$$
\text { Stk }=\frac{\text { Stop distance }}{\text { Filter radius }}
$$

The stop distance, $S_{S}$, is the distance a particle with an initial velocity, $\mathrm{U}_{0}$, will travel horizontally in still air before coming to rest. For low particle Reynolds Numbers (spherical particles conforming to Stokes'Law), 


$$
\text { Stk }=\frac{S_{S}}{R}=\frac{\rho_{p} d^{2} U_{0}}{18 \mu R}
$$

In the general case the stop distance will depend upon the variable drag which changes with the Reynolds Number as the particle slows along its path. It can be shown that the stop distance, $S$, in the very general case is

$$
s=\frac{S s}{R e_{0}}=\int_{0}^{R e_{0}} \frac{24}{C_{d}} \frac{d(\operatorname{Re})}{\operatorname{Re}} .
$$

For particles obeying Stokes'Law,

$$
C_{d}=\frac{24}{\operatorname{Re}}
$$

and Equation 6 reduces to a statement of equality between the true stop distance and the Stokes stop distance.

To provide a general solution for Equation 6 requires an expression for $\mathrm{C}_{\mathrm{d}}$ as a function of Reynolds's Number. An equation for $C_{d}$ was fitted to the data for uniform motion presented by Fuchs [1I] for spherical solid particles:

$$
C_{d}=\frac{24}{\operatorname{Re}}\left[1+\left(a+b R e+c R e^{2}+d \operatorname{Re}^{3}+e R e^{4}\right)\left(\operatorname{Re} f^{\prime}\right)\right]
$$

in which,

$$
\begin{aligned}
& a=1.1204909 \times 10^{-3} \\
& b=1.2008758 \times 10^{-1} \\
& c=2.0444472 \times 10^{-4} \\
& d=2.9734145 \times 10^{-7} \\
& e=1.2782079 \times 10^{-10} \\
& f=2.1210040 \times 10^{-1}
\end{aligned}
$$

In comparison with the large number of empirical formulae for predicting drag coefficients, the equation presented is a single explicit expression applicable over the entire range of normal interest for Reynolds Numbers from 0.01 to 1000. The plot of this equation, along with Fuchs' tabled values, are shown in Figure 3.

The data reported by Fuchs were obtained by averaging the more reliable experimental results. For the tabled values, the probable error in the values 


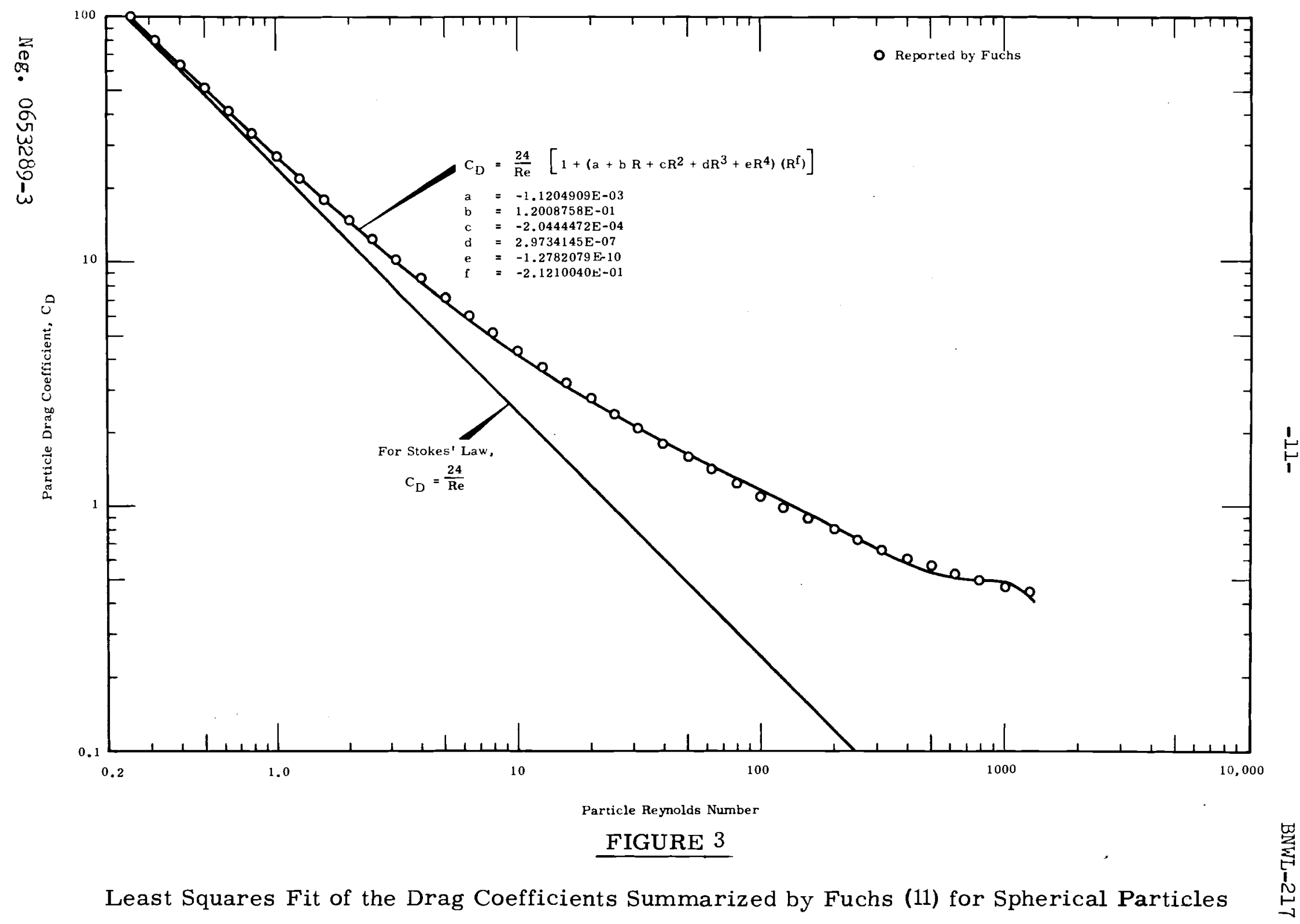


of $C_{\bar{d}}$ is about 1 per cent for Re less than 0.5 and gradually increases with increasing Re to reach 3 - 4 per cent at an Re of 500. The predicted values are within these ranges and show a maximum deviation from the tabled values of 6 per cent at a Re of 1000 .

It was possible through a computer routine to calculate the stop distance using Equations 6 and 8 , and thus determine more accurately the correlating parameter for impaction. In Figure 4 is shown the ratio of the Stokesistop distance to the true stop distance calculated under the assumption that the resistance of air does not depend on acceleration.

It should be remembered that the drag coefficients used are for spherical particles. The particles used in this study were not spherical, but were imperfectly crystalline in form with approximately equal dimensions along the three axes. The departure from truly spherical form is considered to not disqualify the data of Fuchs for application in this study.

The above development for arriving at a more accurate parameter with which to correlate impaction efficiency is not the only approach which could be taken. Brun, et al ${ }^{[34]}$ in calculating impaction on a cylinder, considered a parameter defined by

$$
\phi=9 \operatorname{Re}_{f} \frac{\rho g}{\rho p}
$$

Which allowed for deviations from Stokes Law behavior, Impaction efficiency on a cylinder is shown as a function of the Stokes Iumber with lines of constant $\phi$ as a parameter. For a constant Stokes "Number, the collection efficiency is calculated to decrease as $\phi$ increases.

\section{TXPERIMEITTAL}

Concentration ratios were determined after analysis for the numbers of aerosol particles collected on filters supported within a recirculating wind tunnel. The true air stream concentration was estimated by sampling through a filter at a constant flow rate corresponding to the average air speed. Similarly, a subisokinetic sample was simultaneously obtained. The sampling error was determined by countine and sizing the number of particles collected on each filter。

The particles used were phosphorescent zinc sulfide obtained from the United States Radium Corporation and had a theoretical density of $4.1 \mathrm{~g} / \mathrm{cc}$. 


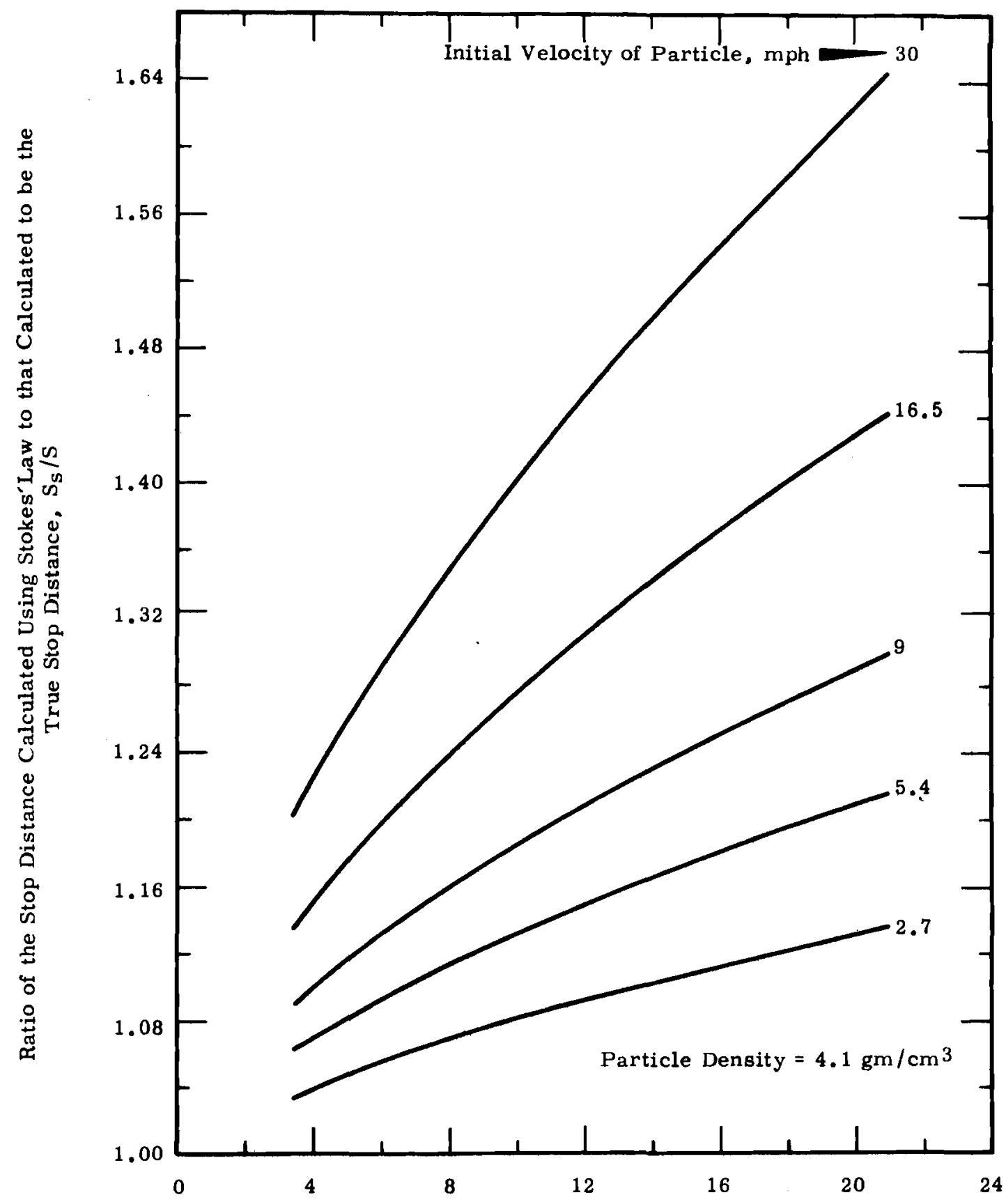

Particle Diameter, microns

\section{FIGURE 4}

Magnitude of Increased Stop Distance Caused by Neglecting Deviations from Stokes Law Behavior for Spherical Particles

Neg. $0652856-18$ 
The zinc sulfide particle size distributions are shown in Figures 5 and 6 as cumulative number and weight distributions. The size distributions are shown to begin at about three microns in diameter since smaller particles were only counted and not sized due to insufficient fluorescent light. Number 2210 has a smaller average particle size than number 2330. A size distribution for a mixture consisting of 45 per cent by weight 2210 , and 55 per cent by weight of 2330, is also shown in the figures. For number 2330, the size distribution was determined by using a commercial particle classifier*. For the other two distributions, the particles collected on a filter were illuminated with ultraviolet light and the fluorescent particles sized using a microscope and a calibrated globe and circle graticule. The particles were sized using an equivalent projected area of a sphere.

The filter holder used is shown in Figure 2. Shown are the assembled polyethylene filter support and its components: a base with its cup-like cavity, a backing for the filter, the membrane filter, a retaining ring to seal the filter edge, and a cover to protect the filter when not in use. The backing consists of a strip of crepe paper continuously wound around a central wooden dowel of 0.53 inch diameter. The dowel reduces flow through the central region of the filter. Air passing through the filter near the perimeter may be diverted slightly outward in a radial direction because of component dimensions. The inside diameter of the cup-cavity which holds the crepe backing is 1.70 inches and the inside diameter of the retaining ring is 1.65 inches, resulting in a 0.02 inch annulus under the lip of the retaining ring through which air flows. The outside diameter of the retaining ring is 2.10 inches and the depth of the retaining ring in front of the filter is 0.12 inch.

The membrane filters were Millipore Type $A A^{* *}(0.8$ micron pore size) except for two cases in which the more open structured Gelman Type AM-1*** filters ( 5.0 micron pore size) were used. These two cases were for the subisokinetic flow at sampling ratios of 0.5 and 0.3 for the $9 \mathrm{mph}$ windspeed.

The recirculating wind tunnel used is shown in Figure 7 and schematically in Figure 8. The air was driven from the blower through a fine mesh with 31 per cent free area to flatten the velocity profile. Next was a 3 foot section of rectangular straightening vanes set at 6 -inch centers. The test filters were located 25 feet downstream of the vanes in the square duct. The filter holders

* Bahco Micro-Particle Classifier No.6000, HoWo Dietert Co。 


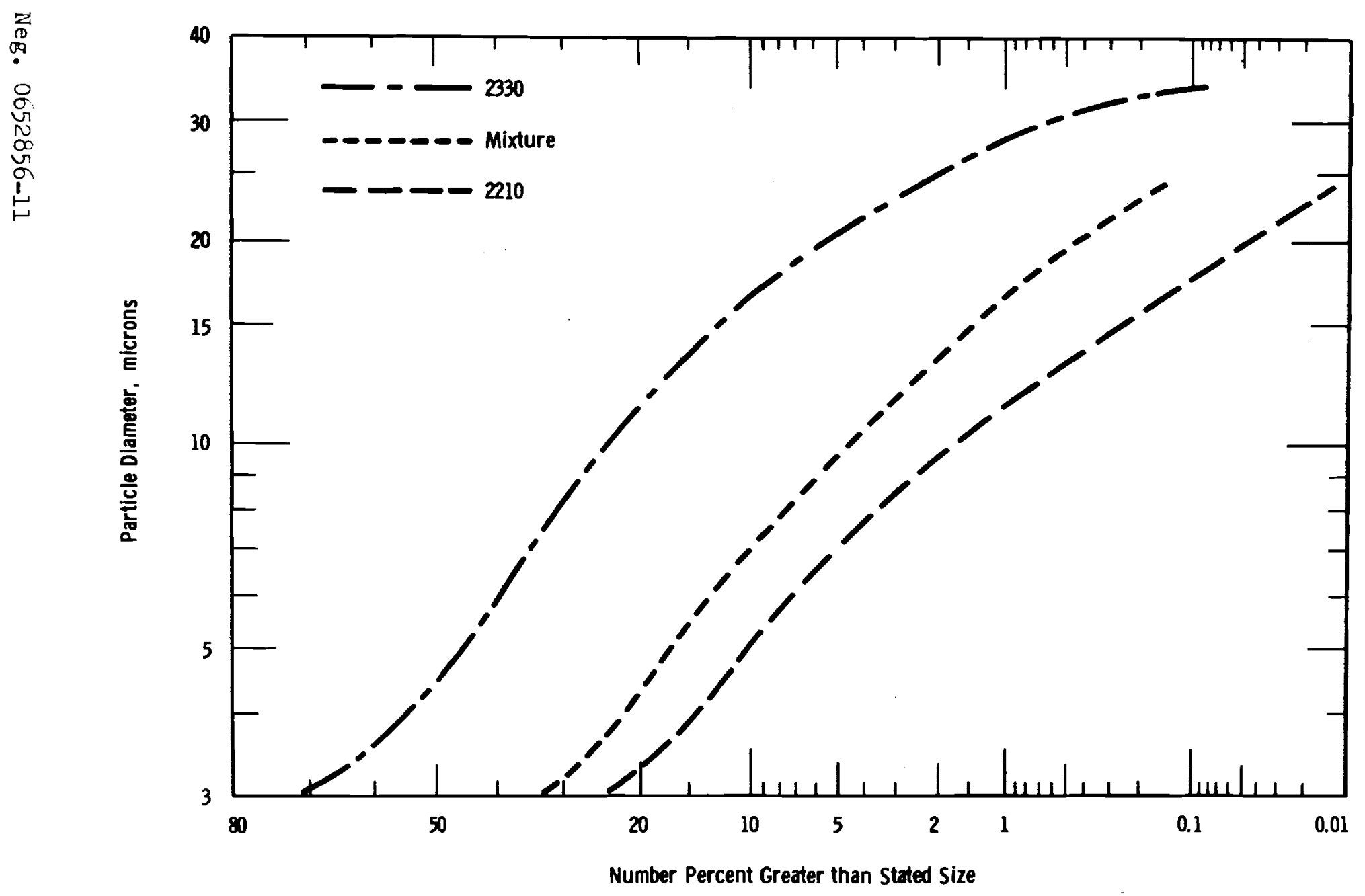

FIGURE 5

Typical Number Distributions for Zinc Sulfide 
0
0
0
0
8
0
$N$
0
0
0
1
5
$n$

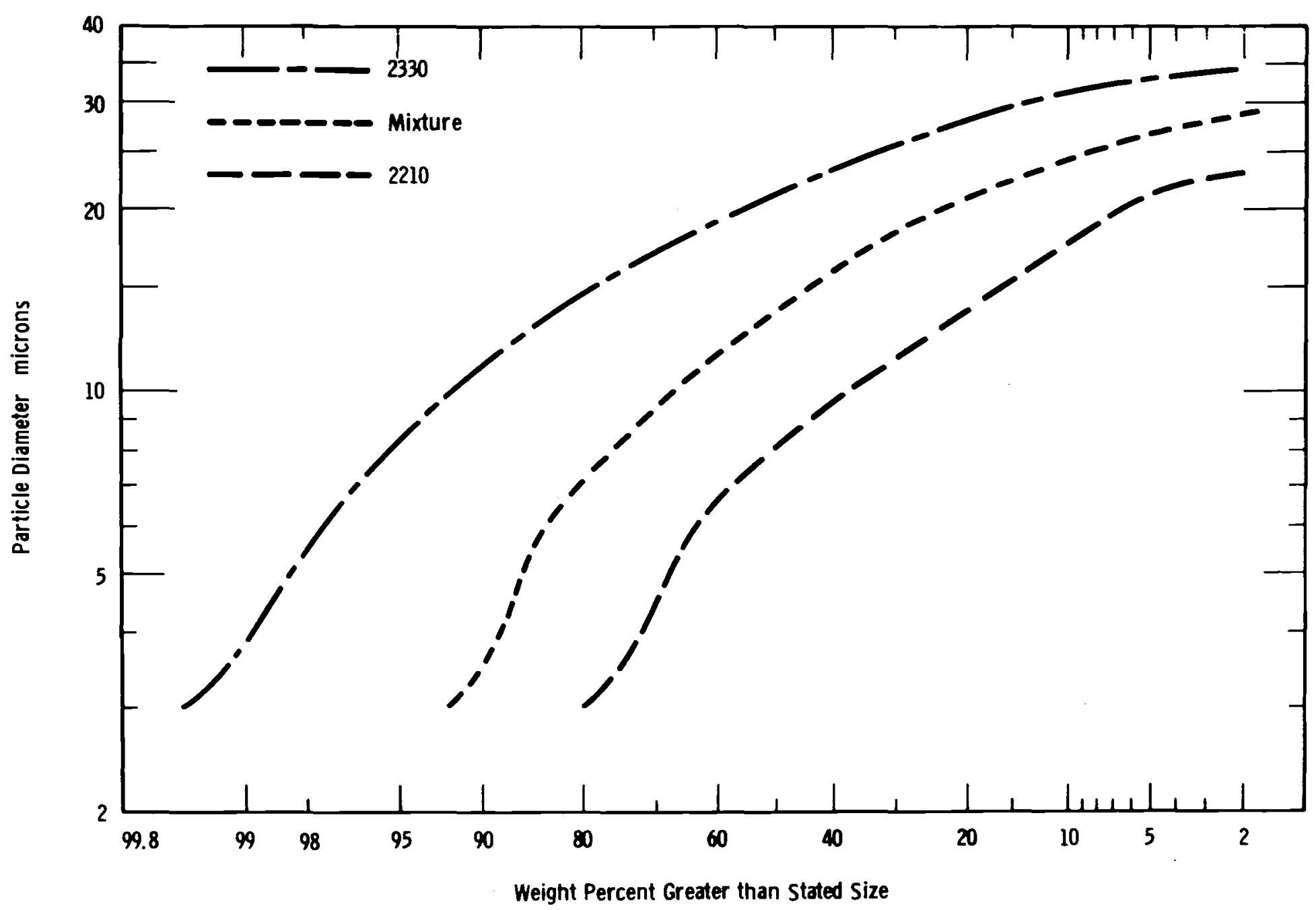

\section{FIGURE 6}

Typical Weight Distributions for Zinc Sulfide 


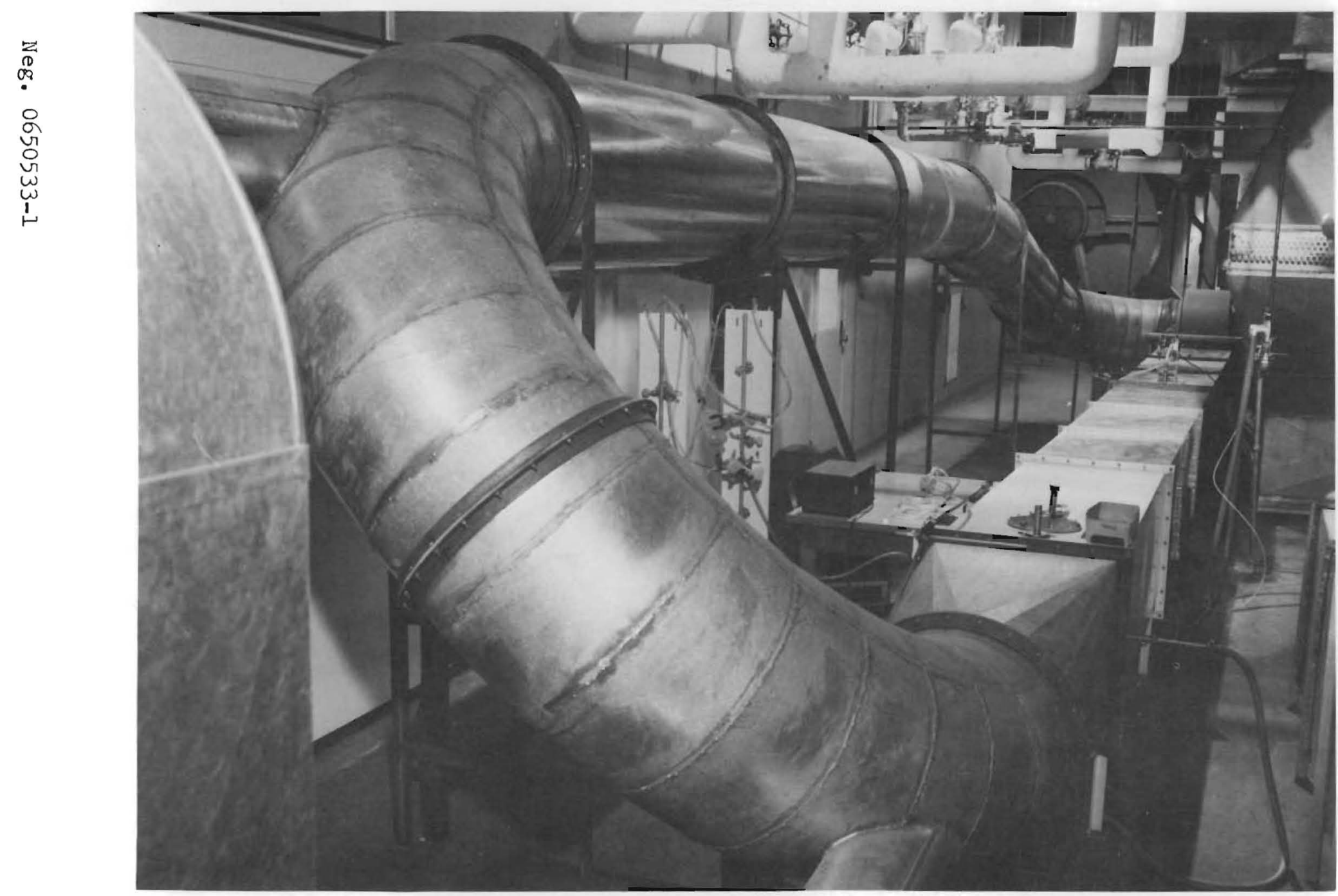

$\stackrel{5}{\stackrel{5}{ث}}$

FIGURE 7

Photograph of Wind Tunnel

穿 


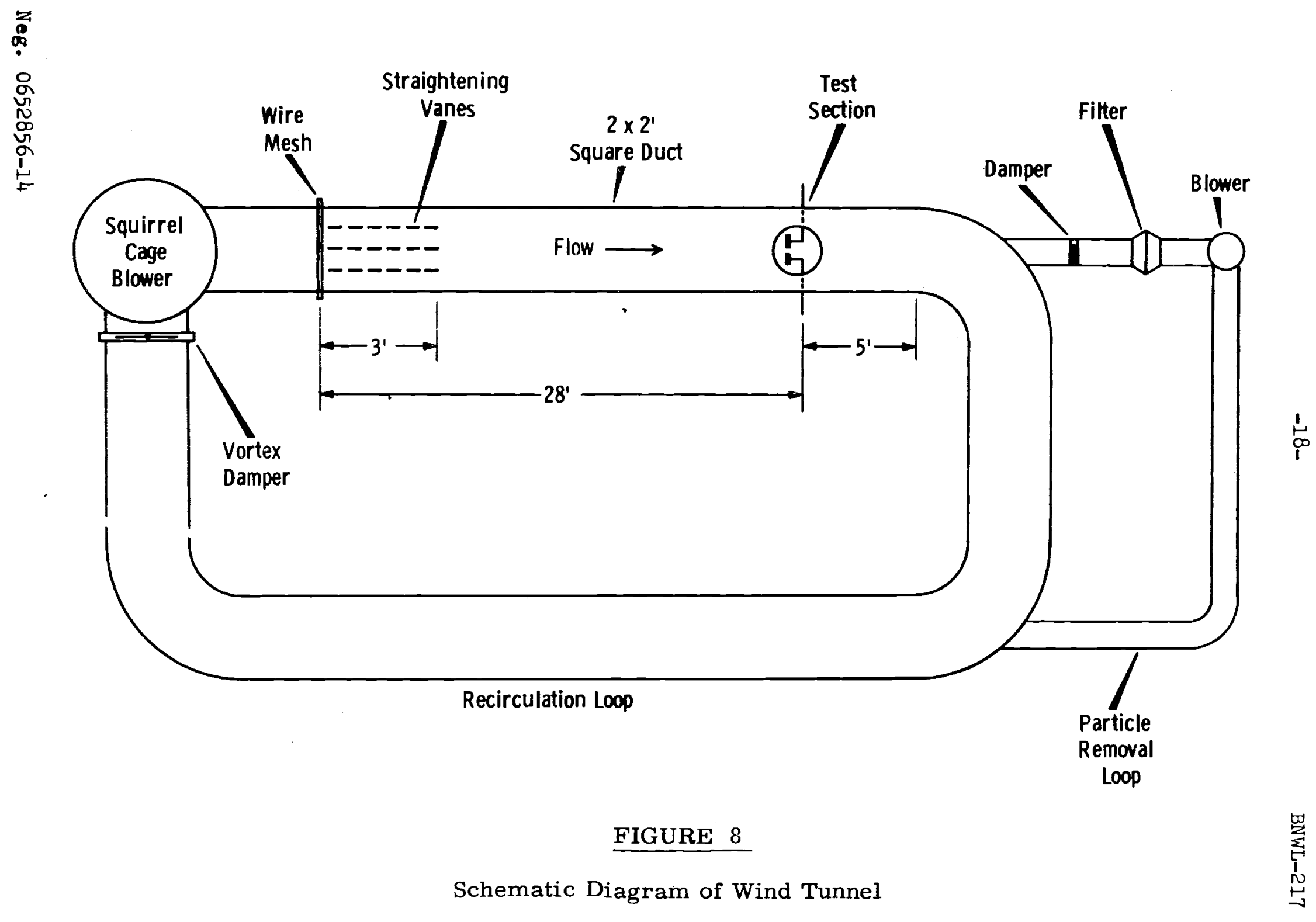


were mounted in rubber receptacles which could contain critical orifices for subioskinetic flow control. The filters were located six inches apart along a horizontal plane and faced into the same perpendicular cross section of the tunnel. This test section is located in Figure 7 below the page number。

For the lower windspeeds, the isokinetic sample was obtained using a modified filter holder. The crepe paper backing was replaced with a fiber glass support in order to have a uniform backing. To improve the aerodynamic performance at the filter edge, the outside edge of the filter holder retaining ring was beveled.

For the higher windspeeds, the maximum flow attainable through the filter was less than isokinetic due to high pressure drop. For these cases, nozzles about three inches long were pressed onto the front of the filter holder. The nozzle entry diameters were smaller than the filter, thus isokinetic velocities could be obtained through the nozzle inlet. This modification is shown in the left side of Figure 9. Particles tended to deposit on the inner surfaces of these nozzles and the amount had to be determined in evaluating the isokinetic sample。

Sampling rates through the isokinetic filters and some of the higher flow rates for subisokinetic filters were controlled by use of calibrated flow tubes. To simultaneously initiate sample collection at isokinetic and subisokinetic flow rates, the rubber-backed metal discs shown in Figure 9 were initially placed over the front of the retaining ring or nozzle and vacuum applied to the sample lines. The vacuum held the discs in place and the discs kept the filters free of extraneous particles until sampling was to begin. The filters were located in the wind tunnel so that the windspeeds at the two filter locations were identical. Air velocities were measured with a precision anemometer* or a pitot tube. Next, the recirculating blower was turned on, the velocity profile checked, and zinc sulfide dust blown into the tunnel.

After the dust was introduced into the tunnel by a Wright** dust feeder, the air was allowed to recirculate two to three minutes to allow uniform mixing and equilibrium of deposition and re-entrainment of particles on the tunnel walls. The vacuum was turned off the filters momentarily which allowed the metal discs to fall off. The vacuum was reapplied quickly and the sampling begun。 Sampling lasted from 10 to 20 minutes depending upon the expected number of particles collected on the filters. * Hastings Precision Air-Meter, Model B-I6A, type SS-22A probe。 ** Messrs. L。Adams, Ltd。, Minerva Road, Chase Estate, London, N。W。 10 


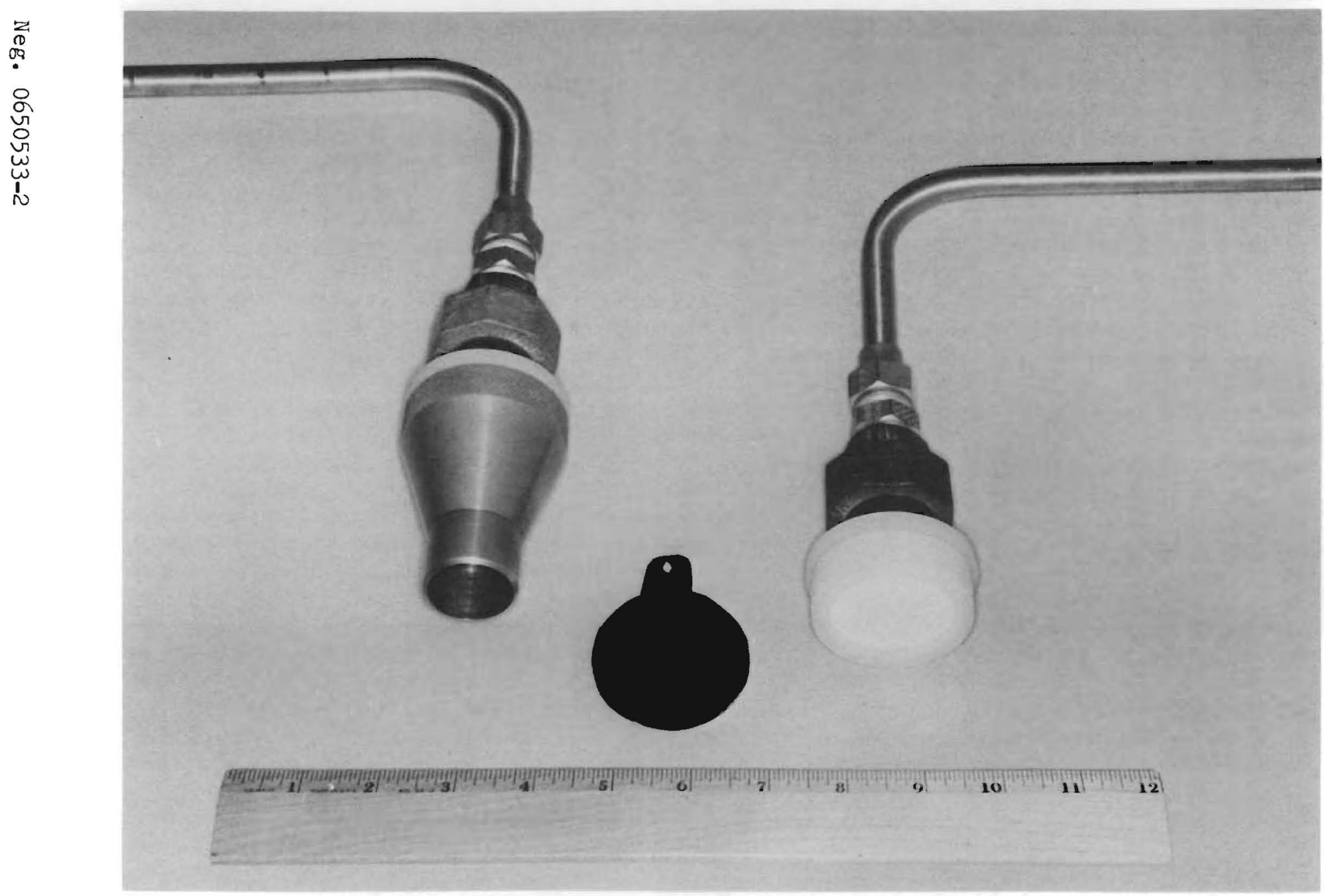

FIGURE 9

Nozzle and Filter Holder Assemblies 
After sampling, the filters were removed from the filter holder and microscopically examined at $250 \mathrm{X}$. The particles were made fluorescent with ultraviolet light and sized by use of the globe and circle eye-piece graticule. [13] The graticule consisted of a rectangular grid subdivided into divisions and had, above and below, a series of graded globes and circles whose diameters were in a progression of the square root of two. The particles were counted and assessed for size by comparison of the equivalent projected spherical area with the appropriate circle, globe or division. Particles were grouped into seven size increments corresponding to the increments on the graticule. The absolute size for an increment was determined by calibration with a stage micrometer. The first increment corresponded to all particles less than 3.2 microns in diameter, while the largest increment coresponded to particle sizes from 17.8 to 25.2 microns in diameter.

Due to time limitations, counting and sizing all the particles on the filter was impractical. Only portions of the filter were counted and the assumption made that the particles counted were representative of symmetrical distributions of particles in concentric annular areas of the filter. The filter was microscopically scanned across the diameter corresponding to the vertical axis during sampling. Depending upon the concentration of particles on the filter, the scan width was 73 microns or greater. The 73 micron scan width corresponded to the distance between two lines on the graticule and was arbitrarily chosen as the minimum width over which variations in the concentration on the filter would be averaged. Typical numbers of particles less than three microns in diameter counted in the 73 micron wide scan were from 800 to 22,000. For the latter number this could correpond to about 160 particles of the fifth interval size。 For the sixth and seventh interval size even fewer particles would have been present. Thus, for these size increments the scan width was increased to obtain a significantly smooth distribution or number of particles as a function of distance across the scan length. Scan widths were increased up to $10 \mathrm{~mm}$ in some cases in order to obtain at least 50 particles of each size in the scan length. If the population density of particles was too low to obtain the 50 particles, one-half of the filter was counted for particles in that size increment. To facilitate the calculation of the total number of particles on the filter from the scans, a computer program was written to perform the calculations. The program utilized the number of particles in each size group counted in an incremental length (approximately $1 \mathrm{~mm}$ ) of the scan. Knowing the radius at which the increment was located and the incremental length, the semi-annular 
area that the increment represented could be calculated. Thus, the total number of particles in that area could be calculated from those on the increment. The calculation is performed similarly for each increment and the results for all the increments summed to yield the number of particles on the filter.

When an entry nozzle was used to obtain the isokinetic sample, particles on a second filter had to be sized and counted. This second filter accounted for particles which deposited on the inside walls of the nozzle during sampling. These were removed and collected on this second filter by an air washing technique. The nozzle was attached to a clean filter, the assembly placed in a vertical position, and air drawn through the filter. An air jet formed from glass tubing was slowly advanced down the nozzle walls. The particles air washed from the walls collected preferentially around the filter circumference. All particles on one-half of the filter were sized and counted. Although a detailed study was not made of deposition in the nozzle, large particles were preferentially deposited on the nozzle walls. Results are shown in Appendix A.

\section{RESULTS AND DISCUSSIONS}

The experimental data are reported as collection ratios for particles actually collected on the filter media, as a function of particle size for each experimental combination of sampling rate and windspeed. These combinations are summarized in Table I. Representative particle size distributions collected on the filters are shown in Figure 10 and representative collection patterns on the filters are shown in Figures 11 and 12. Experimental collection efficiencies are shown in Figures 13 through 18 for 4, 5, 8, 11, 15 and 21 micron diameter particles. These sizes correspond to the integer micron size closest to the mid-point of each size interval counted. In addition to these data points, calculated curves for each sampling rate are also shown as dashed curves in Figures 15 through 18. These curves are calculated, using Equation 1 from the solid lines which represent the impaction efficiencies at each windspeed. For the calculation, the assumntion is made that the impaction efficiency, $\varepsilon$, is independent of sampling rate for any windspeed.

The application of the results to calculation of sampling error correction factors for representative particle size distributions is discussed in the Conclusions. 


\section{TABLE I}

SUMMARY OF OPERATING CONDITIONS FOR COLLECTION

RATIO DETERMINATIONS

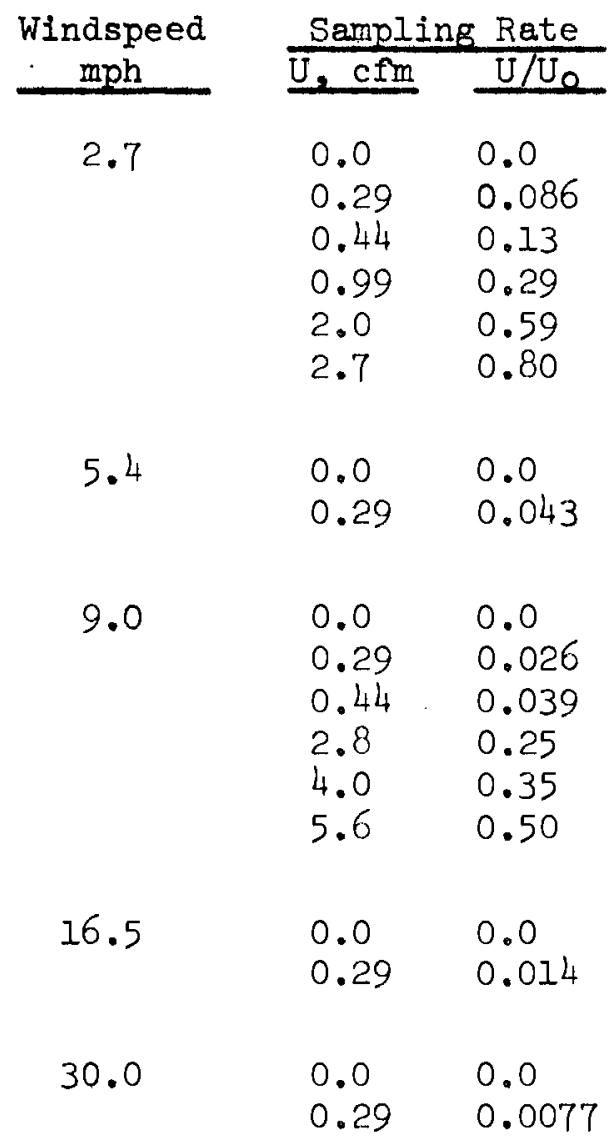




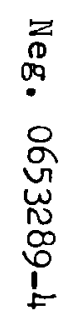

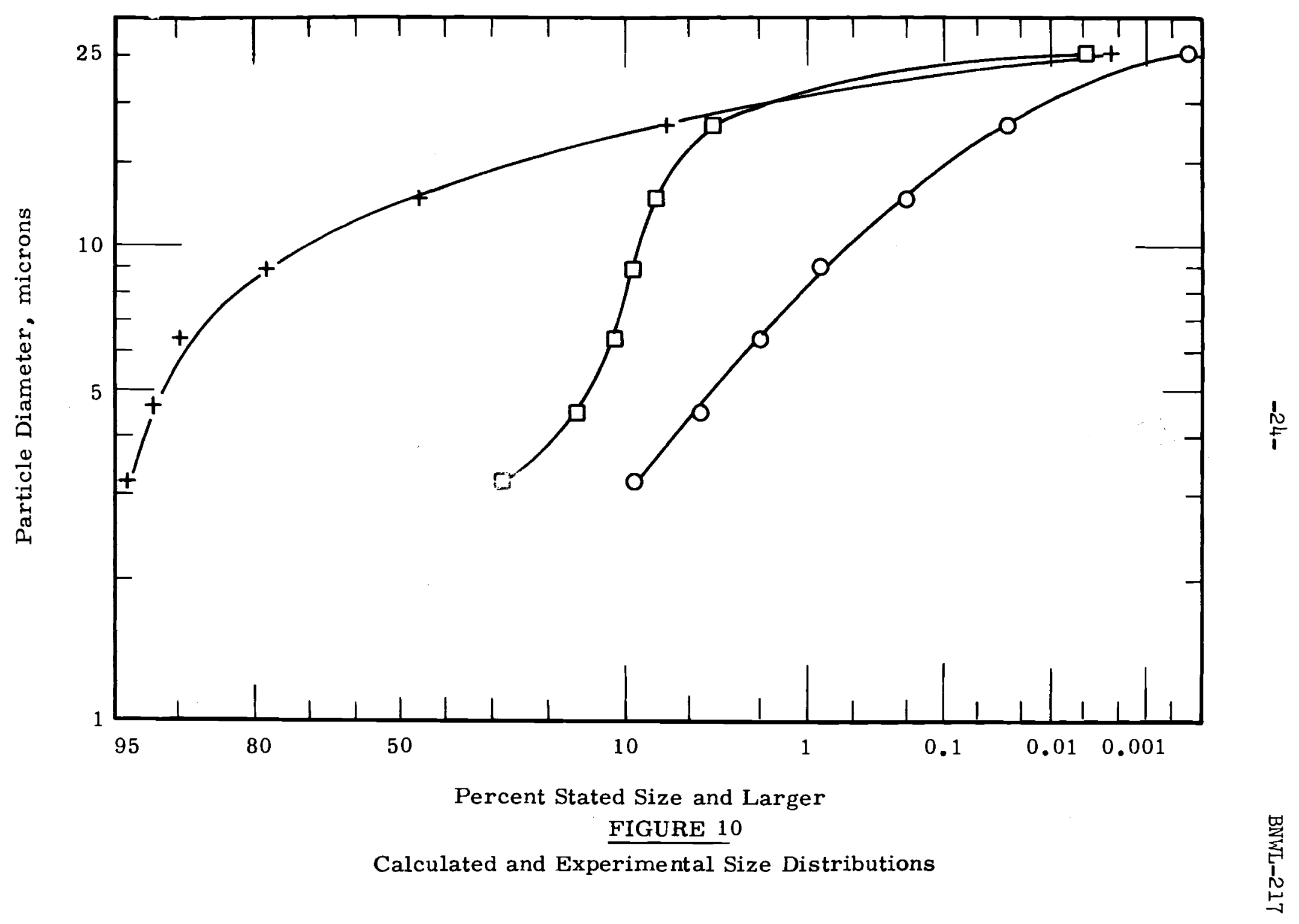


Particle Distribution on Filters

Early in the study it became apparent that particles were not uniformly deposited on the filter and that the non-uniformity was a function of sampling conditions. Moreover, at flows significantly less than isokinetic impaction on parts of the filter holder appeared to be significant. The non-uniformity of collection over the surface of the filter posed a problem in particle sizing and counting and extra care had to be taken to obtain a valid integrated count for the number of particles of a given size on the filter. This condition could not be avoided nor remedied, since it appeared to be caused by the flow patterns resulting from the filter holder geometry .

The significance of the deposition of particles on the filter retaining ring was determined by measuring the fluorescence of the holder with the filter in place and comparing this fluorescence with that from the filter holder alone (filter removed). These comparisons were made for several filters with the Rankin counter, an instrument designed specifically for measuring the fluorescence from particles collected on these filters. [35] Results of these comparisons are shown in Table II. These data show that light emission from particles on the filter holder may be a significant fraction of that from particles on the filter, particularly for very low sampling rates. Since the subisokinetic sampling corrections are applicable only to particles collected on the filter media, some precaution must be exercised in applying the corrections reported to filters evaluated by measuring the fluorescent light emission。

The particle distribution on the filter as well as on the retaining ring is highly dependent on the sampling velocity and the air velccity. Distributions are shown for representative flow conditions by the six filters shown in Figure 1l. The zinc sulfide particles were illuminated with ultra-violet light to make the particles visible in the photographs. A black arrow is marked on the retaining ring to show the top of the filter during sampling. The arrow tip indicates the edge of the retaining ring. These photographs show that particles may be preferentially collected on regions of the filter.

Many filters sinilar to those shown in Figure ll were examined visually for deposit uniformity and collection on the retaining ring. Although the examinations were quite subjective, a general pattern emerged of the 


\section{TABLE II}

REPRESENTATIVE PARTICLE COLLECTION ON RETAINING RING

\begin{tabular}{|c|c|c|c|c|c|}
\hline \multirow{3}{*}{$\begin{array}{c}\text { Sampling Rate } \\
\text { cfm }\end{array}$} & \multicolumn{5}{|c|}{$\begin{array}{c}\text { Percentage* On Retaining Ring of } \\
\text { Total Collection }\end{array}$} \\
\hline & \multicolumn{5}{|c|}{ Windspeed, $\mathrm{mph}$} \\
\hline & 5 & 15 & 25 & 30 & 36 \\
\hline 0.0 & $38-51$ & $33-67$ & $9-67$ & $30-33$ & $13-32$ \\
\hline 0.3 & $5-22$ & 11 & 30 & 14 & $13-20$ \\
\hline 0.4 & $8-16$ & 15 & 29 & 31 & $13-17$ \\
\hline 2 & 1 & 11 & 6 & 25 & $14-23$ \\
\hline 4 & 2 & 6 & 14 & 19 & $5-7$ \\
\hline
\end{tabular}

* Ranges from multiple determinations. The percentages indicate light emission or possibly mass, but not the total number of particles since a size distribution is present. 


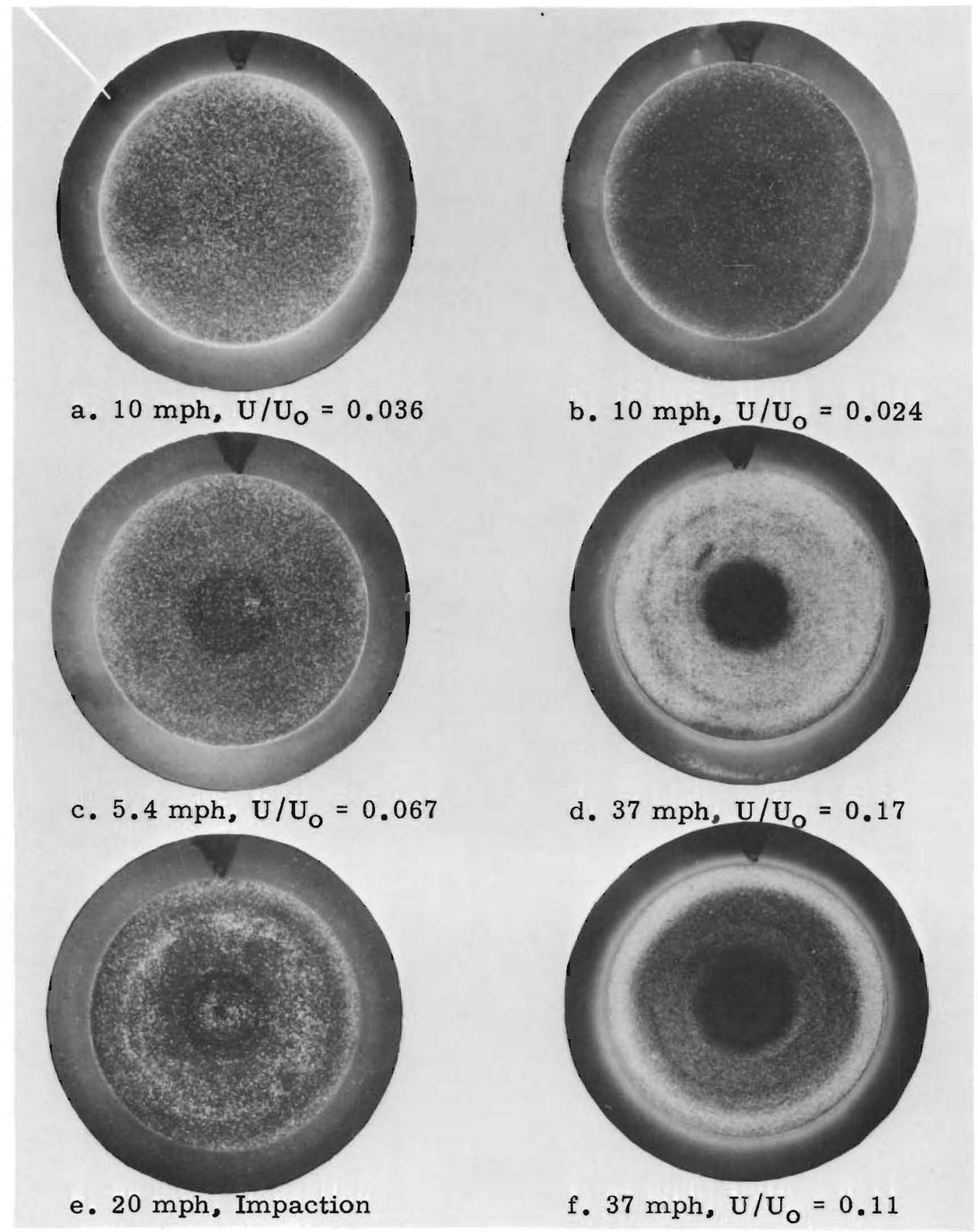

FIGURE 11

Particle Collection Patterns as a Function of Windspeed and Sampling Ratio 
appearance of the deposit as a function of sampling rate and windspeed. These very qualitative relationships are show in Figure 12. In this diagram, three general regions are defined: (I) a region of uniform distribution of particles across the filters, (2) a region in which particles are preferentially collected around the filter edge, and (3) a transition region in between. For low windspeeds and all sampling rates the particles appear to be evenly distributed across the filter face, except for the central portion of the filter. At the higher windspeeds an annular ring of a heavy concentration of particles is formed around the filter circumference. The shaded area approximates the region midway between the two extremes.

A conclusion that may be drawn from Figures 11 and 12 is that the differential deposit per unit area and probably the integral collection ratios over the filter are a function of air velocity as well as particle size, since the collection pattern is a function of the windspeed.

\section{Impaction Efficiencies}

Impaction efficiencles are shown in Figure 13, as a function of the adjusted Stokes Number, $S / R$, with windspeed as a parameter. As shown by comparison with Figure 14, the adjusted Stokes Numbers correspond to particles of $4,5,8,11$, and 21 microns in diameter. These particle sizes are based upon the diameter of a circle having the projected area of the particle and the effect of non-sphericity of particles is neglected in calculating Stokes Numbers.

The data points show experimental scatter from which a consistent trend must be determined. To determine the trend, an analysis was made utilizing the facts that: (1) the impaction efficiency should continuously increase with the value of the stop distance, (2) the impaction efficiency should continuously decrease with windspeed at a constant particle stop distance by analogy with Brun et al ${ }^{[34]}$ calculations for impaction on a cylinder, and (3) the impaction efficiency should be relatively independent of windspeed at sufficiently large stop distances, and (4) the trend must take into consideration the collection patterns of Figures 11 and 12 .

Taking these facts into consideration one must immediately eliminate the possibility of trying to represent all the impaction efficiency data as a single line of efficiency versus particle size even though a rather general trend is obtained by such a procedure. The curves shown in 


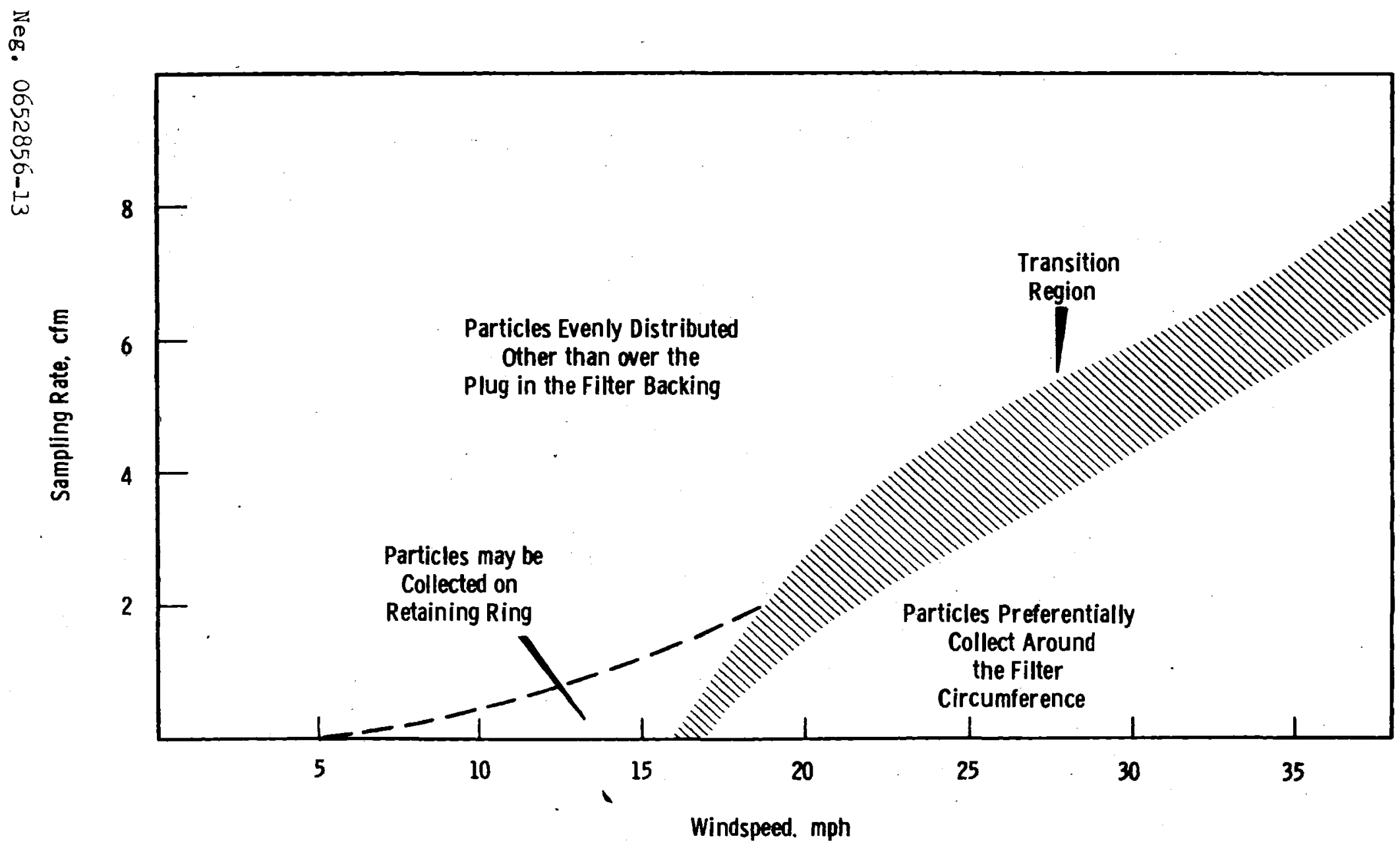

FIGURE 12

Effect of Velocities on Visually Determined Particle Distributions on Filter for Particle Size Distributions 


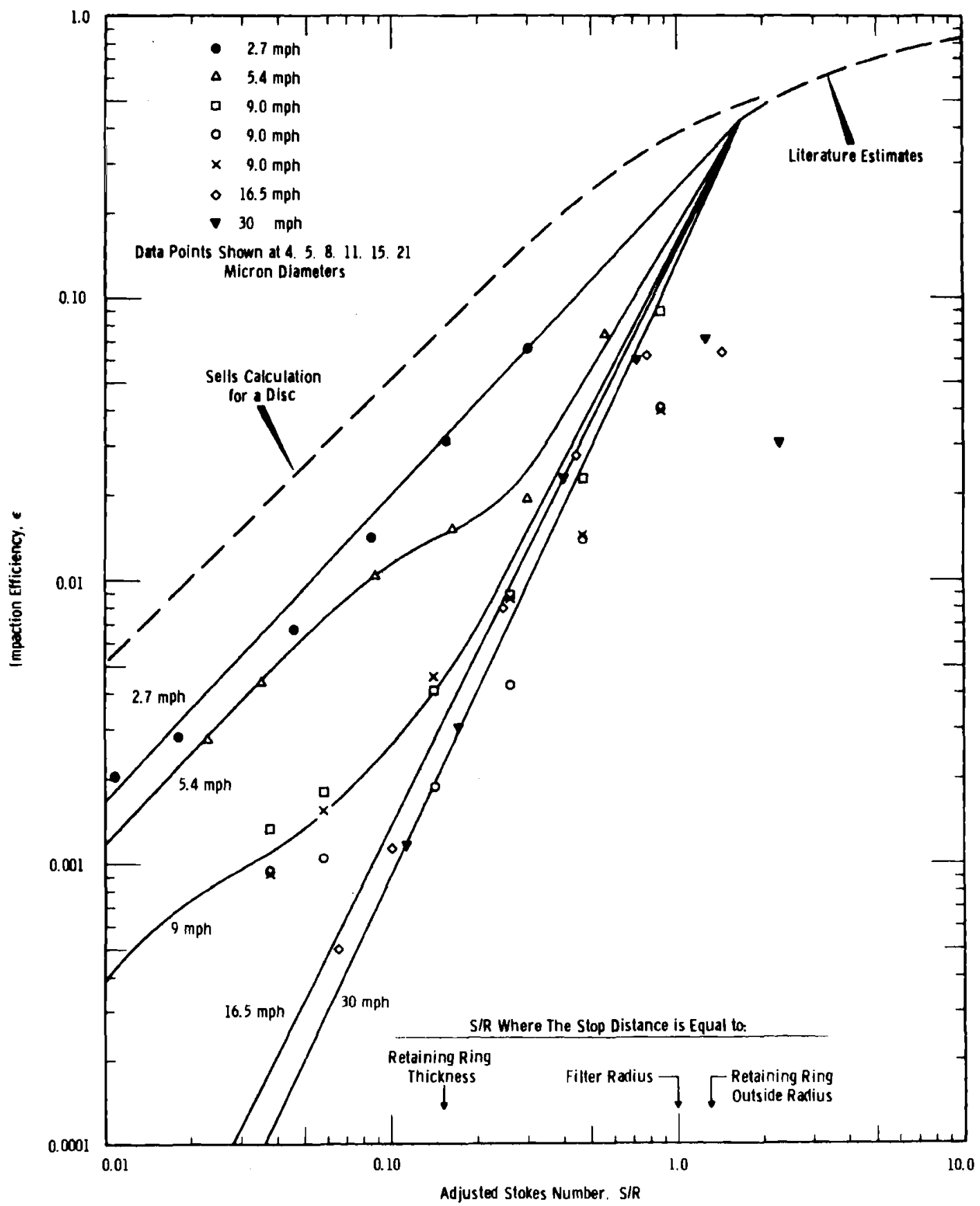

\section{FIGURE 13}

Inertial Deposition of Particles on Filters as a Function of Windspeed

Neg. 0653289-2 


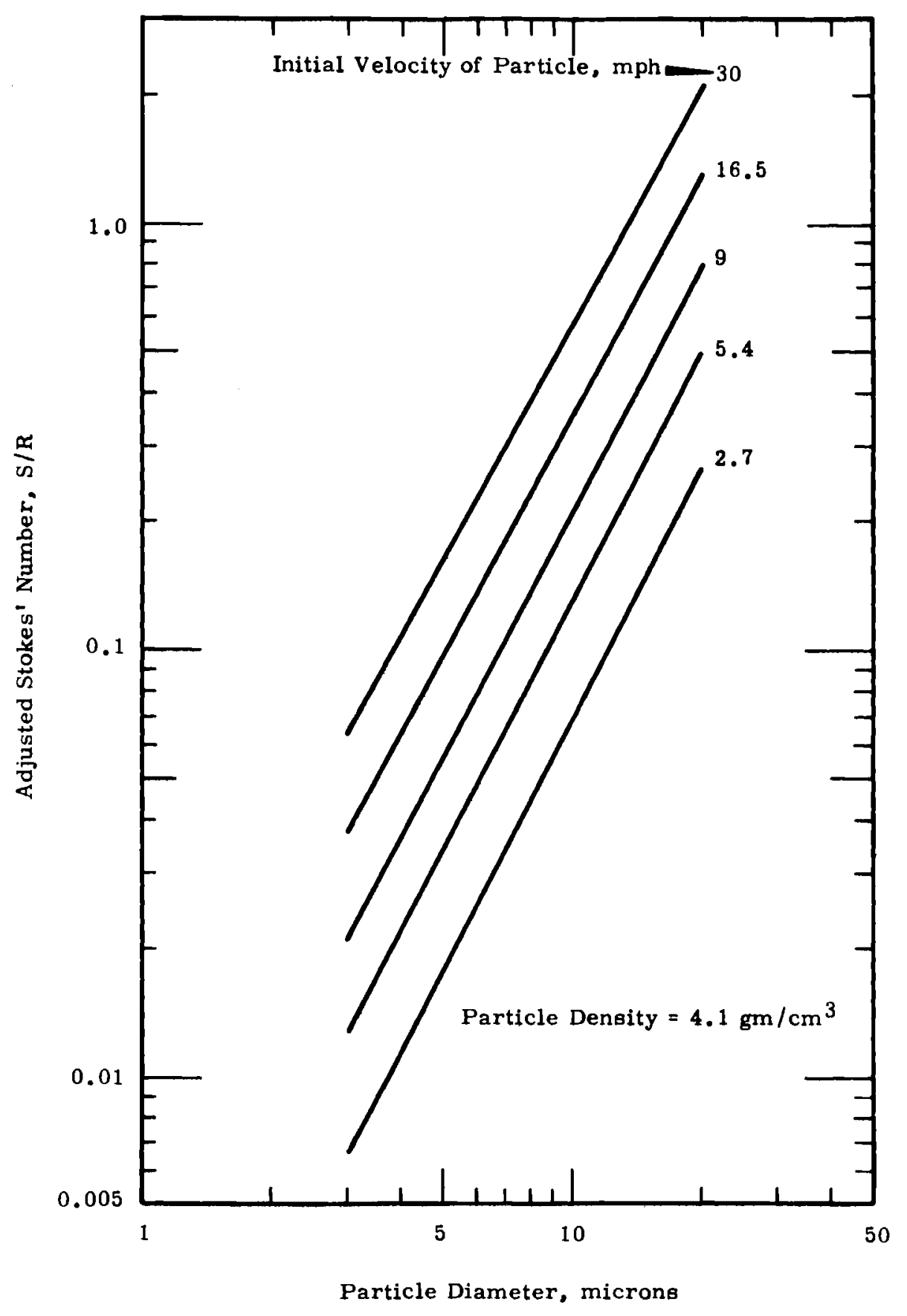

FIGURE 14

Adjusted Stokes' Number as a Function of Particle Size and Initial Velocity for Spherical Particles 
Figure 13 are considered to be as nearly fit to the data as experimental errors will allow and within the framework of the foregoing assumptions.

The curves intersect at approximately a Stokes'Number of 1.8 and an impaction efficiency of 0.45 . The intersection is seen to lie near the line predicted by Sell[4] for impaction efficiency on a disc. The intersection is also approximated by the general trend for $\varepsilon$ obtainable as a literature estimate from the data of Watson [8], Badzioch [7], and Hemeon and Haines [6] for finite sampling rates. The experimental points are seen to be located below Sell's theoretical curve, but the slope is almost the same for the $2.7 \mathrm{mph}$ windspeed. Additional experimental data ${ }^{[5]}$ for impaction on discs would also suggest that the impaction efficiencies are less than predicted by Sell.

Since the curves tend to intersect at a Stokes'Number, $S / R$, of approximately 1.8, this would suggest that the air starts to diverge around the filter at only about 1.8 radii upstream of the filter and/or the combination of variable points of divergence and the effect of the retaining ring cause the same total impaction on the filter for all windspeeds.

The reason for the experimental collection efficiencies for windspeeds of 16.5 and $30 \mathrm{mph}$ to show a maximum at a Stokes' Number greater than about one is not clear. Several possible mechanisms to explain these maxima have been considered. These include the explanation that the large particles may be re-entrained, move across the filter, then impact on the retaining ring. It is observed that many large particles are collected on the filter under the retaining ring and hence some transfer and impaction on the ring may be a reasonable assumption.

The observed maximum in the impaction data may be caused by some large particles which hit the subisokinetic filter at near windspeed velocity and hence have sufficient energy to break up or become imbedded in the impaction filter. Thus, some of the large particles may be counted as smaller particles. In contrast the particles within the isokinetic nozzle would hit t... nozzle effect on air velocity and hence not be broken or imbedded. If such were the case, the maximum could be explained. Microscopic examination of the filters has suggested neither break-up patterns for particles nor implantation within the 0.8 micron pore size filter used. 
exists at the entrance to the 0.43- and 0.56-inch diameter isokinetic nozzles. If this were so, the largest particles might traverse the turbulence due to their large stop distance and hence a representative sample of the large particles would be collected on the filter. Similarily, the smallest particles would essentially follow the motion of the air and a representative sample would be collected. In contrast an intermediate sized particle might have a stop distance such that it would follow the radial movement of the turbulence at the nozzle entrance and be thrown away from the nozzle entrance resulting in a small number of particles being collected on the filter. If this latter were the mechanism for the maximum, the true impaction efficiencies would tend to be curves without maxima and the true curves would tend to go through the data for the small and large particles and neglect the data for the intermediate sizes. It is unknown if any of the possible explanations are fustifiable or if the maxima are caused by experimental error.

A change of slope for a single windspeed appears to occur for a stokes' Number of about 0.1 to 0.2 . This corresponds to the value of stk corresponding to the thickness of the retaining ring.

\section{Collection Ratios}

The collection ratios for impaction and at subisokinetic sampling rates are shown for constant windspeeds in each of Figures 15 through 18, as a function of particle size with sampling rate as a parameter.

The data show scatter which would indicate deviation from the expected trend. The expected trend can be determined by considering the equation

$$
\frac{\mathrm{N}}{\mathrm{N}_{0}}=\frac{\mathrm{U}}{\mathrm{U}_{0}}+\varepsilon\left(1-\frac{\mathrm{U}}{\mathrm{J}_{0}}\right)
$$

in which the value of the impaction efficiency is assumed independent of the sampling rate. In this case, the values of $\varepsilon$ can be assumed equal to the impaction efficiencies indicated by the solid line in Figures 13 and 15 through 18. Since $\varepsilon_{\text {Impaction }}$ would be very small for one micron diameter particles, the expected value of the collection efficiency, N/NO, is the same as the value of the sampling ratio, $U / U_{O}$, for particles of the order of one micron in diameter and smaller. This means that the particles have negligible inertia and that the particles follow the motion of the air stream. Neglected in this discussion is the influence of electrostatic 


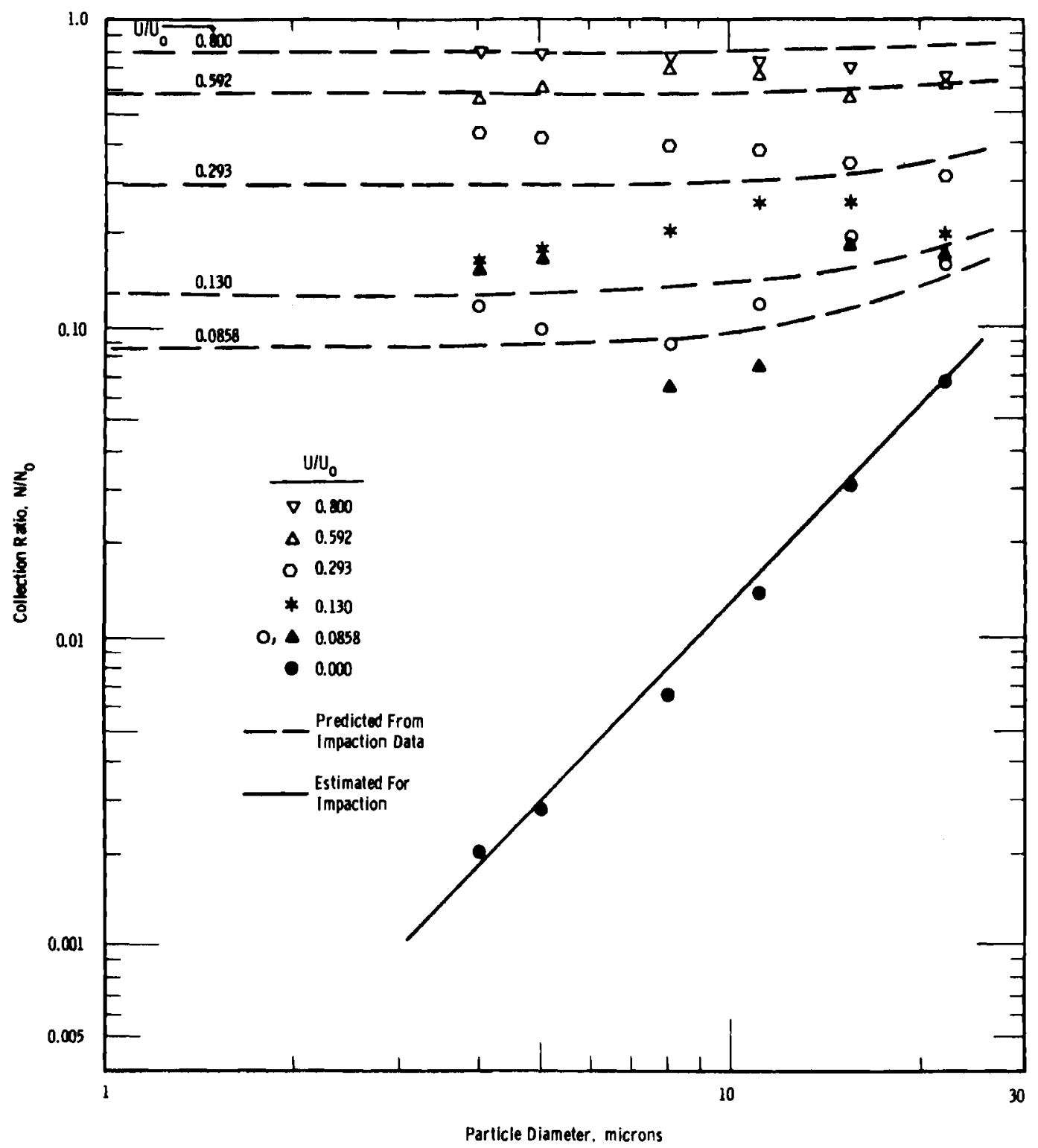

FIGURE 15

Collection Ratio for each Particle Size as a Function of Sampling Ratio $\left(U / U_{o}\right)$ for a $2.7 \mathrm{mph}$ Windspeed 


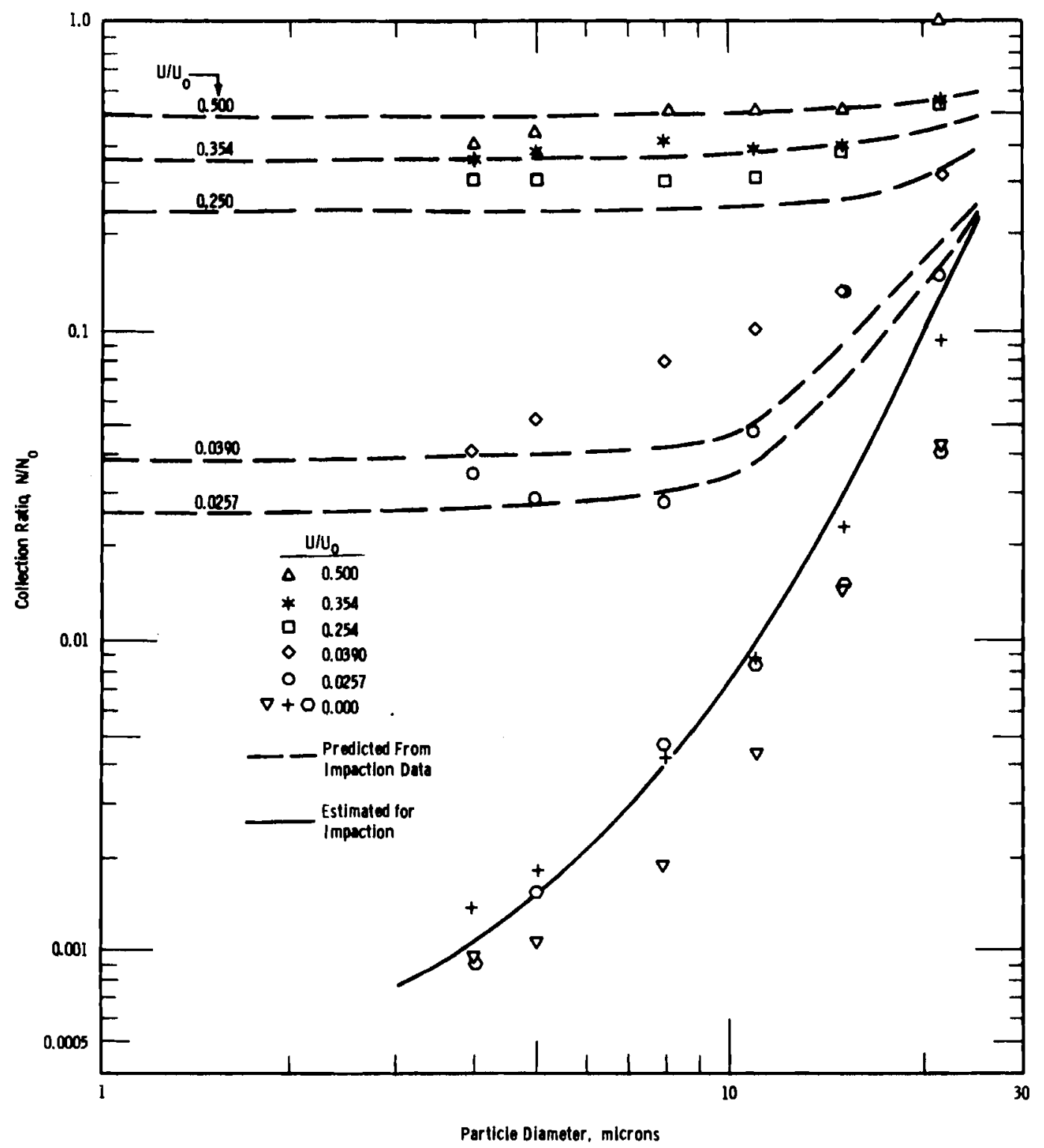

FIGURE 16

Collection Ratio for each Particle Size as a Function of Sampling Ratio $\left(U / U_{O}\right)$ for a $9 \mathrm{mph}$ Windspeed 


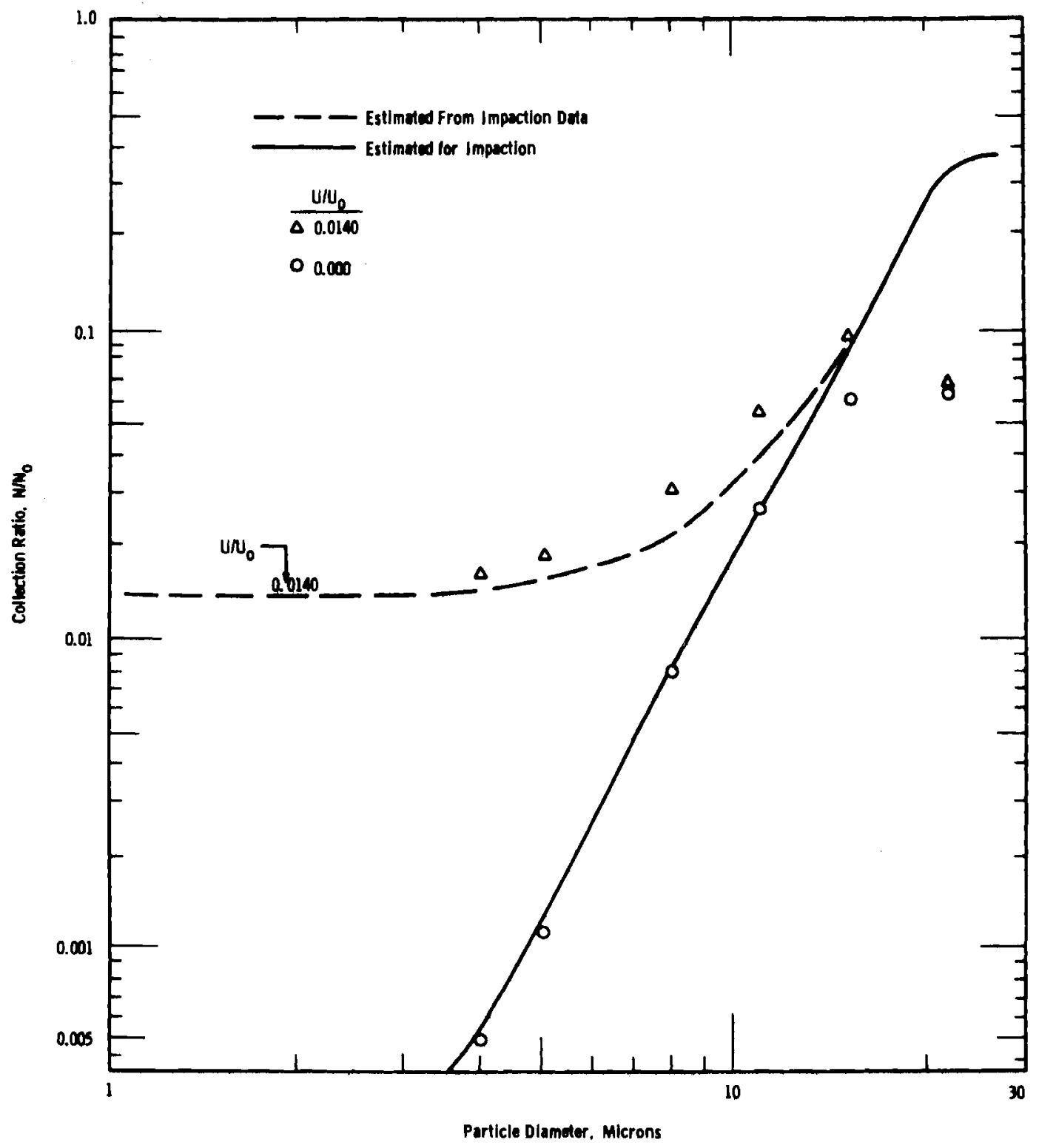

FIGURE 17

Collection Ratio for each Particle Size as a Function of Sampling Ratio $\left(U / U_{O}\right)$ for a $16.5 \mathrm{mph}$ Windspeed 


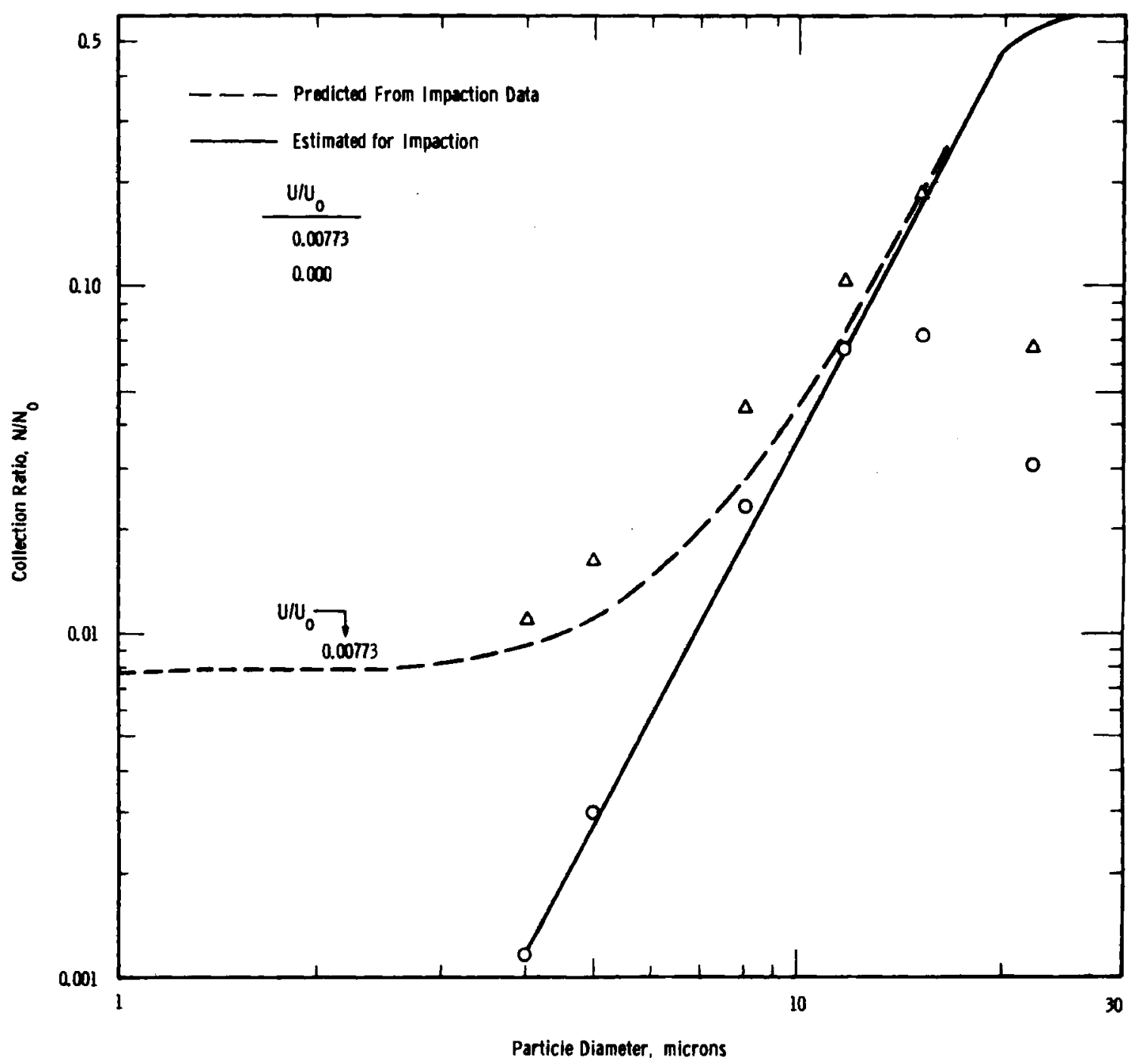

FIGURE 18

Collection Ratio for each Particle Size as a Function of Sampling Ratio $\left(U / U_{O}\right)$ for a $30 \mathrm{mph}$ Windspeed 
effects, turbulence, and particle diffusion upon collection ratios. For very small particles, these mechanisms could be becoming increasingly important in causing a collection ratio deviation above the value of $\mathrm{U} / \mathrm{U}_{0}$. For large size particles, the effect of inertia becomes increasingly important. The collection ratio increases above the value of $U / U_{0}$ as particle size increases. At a particle size of the order of 100 to 500 microns in diameter the collection ratio approaches unity due to the large particle inertia.

The dashed lines for each indicated sampling ratio in Figures 15 through 18 were calculated by assuming the equality of impaction efficiencies for all flow rates at each windspeed. Constancy of impaction efficiency should not be expected, $[7,9]$ but the collection ratio data are not consistent enough to determine the dependency of $\varepsilon$ on $\mathrm{U} / \mathrm{U}_{0}$. To have determined this dependency would have required accuracies in $N / N_{0}$ of better than one per cent compared to the 10 to 20 per cent or more that were obtainable at the higher flow ratios. In fact, $\varepsilon$ can be determined to increase with $U / U_{0}$ for the lowest sampling rates of 0.3 and $0.45 \mathrm{cfm}$. This apparent increase in $\varepsilon$ with $U / U_{O}$ is supported by calculations ${ }^{[9]}$ for sampling from a frictionless ideal fluid through a nozzle of negligible thickness. However, the conparison is only qualitative since the filter has a finite width retaining, ring and since viscosity should be important for the low experimental $U / U_{0}$ ratios. Nevertheless, the use of Equation 1 with the impaction data should give a lower limit to the true collection ratios. The dashed curves are seen to approximate the trends shown by the data points. In general the calculated collection ratios are less than the experimental data.

\section{Error Evaluation}

The collection efficiency data scatter may be interpreted to mean that an appreciable experimental error exists. The control of sources of experimental error will be discussed.

Flow Control

The sampling rates were controlled by critical orifices or by controlling the pressure drop across calibrated flow tubes. For the case of the flow tube, a valve in the vacuum line was preset to the desired flow rate with a dummy filter in place. In starting the sampling, due to variations in the flow resistance between filters, the vacuum valve usually had to be readjusted to obtain the desired flow. Readjustment 
time usually took less than one-half minute. The sampling flow was constant and no attempt was made to try to match the instantaneous fluctuations of the turbulent air flow which would affect the total collection. Sampling was controlled to within three per cent of the desired flow rate.

For sublsokinetic flow rate control, the critical orifices were satisfactory for the lower flow rates for both types of membrane filters used. For flow rates from 2 to $4 \mathrm{cfm}$, the orifices were critical for only the more open structure of the two membrane filter types used.

The air flow within the wind tunnel was controlled by the setting of a vortex damper and the maximum flow rate range was from 2.7 to 37 mph. The uniformity of the velocity profile across the tunnel at the test section was a function of the windspeed. The scale of turbulence was high at the lower windspeeds unless the fine mesh was in place.

This mesh flattened the velocity profile and reduced the scale of turbulence. The reduction in scale is qualitative since the measuring device was not designed for turbulence measurements. [36]

Particle Size Distribution

Since the particles are microscopically counted in size intervals, a method is required to determine the number of each size particle. One method of doing this is to plot the size distribution as the cumulative percentage of particles larger than each size increment on log-probability paper. If the data were to indicate a linear relationship, interpolation is easy. In the present case, the relationships were far from Iinear as shown in Figure 10.

In addition the distributions in general did not fit any of the standard distributions which include:

(1) Log-normal [37]

(2). Mixed exponential $[37,38]$

(3) Mugele-Evans upper-limit function $[37,38]$

(4) Normal $[37,38]$

(5) Nukiyama-Tanasawa $[37,38]$

(6) Rosin-Ramler $[37,38]$

(7) Weibull ${ }^{[39] \text {. }}$ 
Thus, a method ${ }^{[40]}$ was developed to yield an analytical expression for the particle size distributions between the limits of the experimentally determined size range. The method is based on a first estimation of the size frequency distribution, integration to determine the calculated number of particles in any size range, comparison with the experimentally determined number of particles, and iteration until the size distribution as determined by least squares techniques converges. Application of computer techniques facilitates the calculations.

In developing the method of calculation, the observation was made that the logarithm of the quotient of the percentages of particles in any size increment divided by the width of the size increment in microns, was nearly linear with the particle size at the midpoint of the increment or at most could be represented by a cubic expression on semi-log paper. The cubics approximated the true size distributions.

The method is to use these quotients and to calculate a least squares curve through the average particle size in each size increment. The analytical least squares curve is integrated to obtain the calculated number of particles in each size increment. Next, the calculated, CALC, and experimental percentage, EXP, in each size increment are compared and the comparison used as a basis for the first iteration. That is for each average size, $\bar{X}$, in an increment, $\Delta X$, the next estimate of the frequency distribution, $f$, at $\bar{X}$ is

$$
f_{i+1}=f_{i}+\frac{E X P-C A L C}{\Delta X} .
$$

The calculation is repeated and by the fifth iteration a well defined curve is observed.

The method allowed smoothing of the data as shown by comparison of typical calculated and experimental results in Figure 10. Use of these analytical distributions permitted calculation of the collection ratios, $\mathrm{N} / \mathrm{N}_{0}$, for $4,5,8,11,15$ and 21 micron diameter particles which correspond to the integer micron size closest to the mid-point of each size interval counted.

\section{Reproducibility of Data}

The first criterion in determining collection efficiencies is that the distribution of particles, in the air, must be the same for both 
filter locations within the wind tunnel. This uniformity was determined for each windspeed by simultaneously collecting samples with two filters through which the flow rates were equal. The filters were located in the same positions at which subsequently the subisokinetic and isokinetic samples were to be collected. The two filters were analyzed microscopically. Particles between 17 and 25 microns in diameter were counted on one-half of each filter and the counts compared using a chisquare test. If a significant difference in the counts were noted, the filter holder locations were considered to be non-identical and the filter holder locations were changed in an attempt to obtain identical samples. Although the particle concentration in the tunnel was found to be dependent upon sample location, locations were always found which would indicate equal concentration.

The particle concentration and size distributions upon the filters were such that from few to many particles were on the filter. Since the number of particles present might bias the results of the microscopic counting, strips across several filters were recounted several times. The number counted in each size interval was not the same each time, but the average distributions were the same when the sizes at the ends of each size increment were considered. That is, a particle of a border-line size between two size increments might be recorded in the smaller size increment one time and the next time be reported in the larger size increment. If the borderline case consisted of an error of one-half micron in size, all recounts were found to yield the same size distributions.

The reproducibility between runs showing the accumulation of all errors can be estimated by the three impaction runs at $9 \mathrm{mph}$, shown in Figure 16. The collection efficiencies are seen to vary by up to a factor of two. The reasons for this factor are not apparent since for these three runs the filters were located at the same position in the wind tunnel and the flow rates were the same. Counting all the large particles on two filters taken at these locations had previously indicated reproducible conditions at these locations. Thus, the variations could probably have been decreased if time were available to count increasingly larger portions of all the filters. However, the reason for the variation is not firmly established unless changes in humidity and electrical properties were important, or a very small leak existed 
downstream of the filters which permitted air to flow through the impaction filters. The possibility of leakage is considered nil.

If this same variation were to extend over to the subisokinetic sampling rate cases, the experimental variation in collection ratios might well be included within the factor of two variation. However, the experimental collection ratios do not always show a steady decrease with particle size as would be expected if particle inertia were the only cause for particle collection from the annular air.

\section{CONCLUSIONS}

Application of the experimental results to interpretation of any subisokinetic sampling conditions for the filter system under study would ideally require that the subisokinetic samples be obtained in comparable air conditions as in the experimental wind tunnel. That is, the primary restrictions are that the sampled air would have: (I) a constant velocity, (2) the same turbulence characteristics, (3) been directed into the filter face, and (4) the particle density would be the same as for the zinc sulfide. Second order restrictions include that the electrical properties, relative humidity, particle sphericity, and the influence upon velocity profiles of objects near the filter would be comparable to those in the wind tunnel. The effects of variations of these restricting properties on collection ratios are unknown, but for comparable zinc sulfide particles these restrictions should not be excessivley limiting in application of the experimental results.

The application of the data to subisokinetically obtained samples of zinc sulfide under the previous restrictions will be considered. The data heretofore discussed show the marked dependence on sampling error of particle size. Thus, in interpreting $a$ subisokinetically sampled filter, either the number of each size particle collected on the filter must be determined, or the total mass of material collected must be determined and an assumption made as to the true particle size distribution in the air。

First, the case will be considered in which the number of each size particle collected on a subisokinetic filter has been determined. For interpretation of the data, the collection ratio must be determined for each size particle from

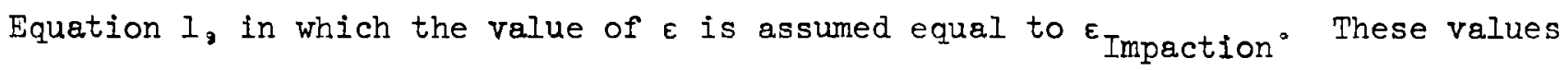
for other than the experimental windspeeds can be estimated by interpolation 
between the curves of constant windspeed for the impaction efficiencies shown in Figure 13. Once $\varepsilon$ and $N$ are known, Equation 1 is rearranged to obtain the number of particles collected, $N_{0}$, which would have been collected on an isokinetic sample,

$$
N_{0}=\frac{N}{U / U_{0}+\varepsilon\left(1-U / U_{0}\right)}
$$

Now, knowing the subisokinetic sampling time, $t$, and the isokinetic sampling rate, $U_{O}$, one can calculate the true air stream concentration,

$$
C_{0}=\frac{N_{0}}{\mathrm{U}_{0} t}
$$

The value of $\varepsilon$ can range from zero for particles of negligible inertia to 1.0 for particles of large inertia. With $\varepsilon$ equal to zero, the calculated collection on an isokinetic filter would be

$$
N_{0}=N\left(\frac{U_{0}}{U}\right)
$$

or the ratio of the apparent to the true air stream concentration would be

$$
\frac{\mathrm{C}}{\mathrm{C}_{\mathrm{O}}}=\frac{\mathrm{N}}{\mathrm{N}_{\mathrm{O}}} \frac{\mathrm{U}_{\mathrm{O}}}{\mathrm{U}}
$$

That is, $C$ equals $C_{0}$ for the case in which $\varepsilon$ equals zero. For the system under study, the value of $\varepsilon$ is greater than zero. Thus, one is interested in the concentration ratios, $\mathrm{C} / \mathrm{C}_{\mathrm{O}}$, that would be calculated from Equation 15 for the experimental values of $N / N_{O}$. The value of $N / N_{O}$ was calculated from Equation 1 , using the smoothed curves of $\varepsilon_{\text {Impaction }}$ for the experimental values of $\varepsilon$. The results of these concentration ratio calculations for particle sizes of 3,5 , 10, 15, and 20 micron diameter and 2.7, 5.4, 9.0, and 16.5 and $30 \mathrm{mph}$ are shown in Figures 19 through 23. As can be determined from an inspection of these figures, the apparent concentrations calculated from Equation 15 can be very much larger than the true concentration. For example, the calculated concentration is

$$
\mathrm{C}=64 \mathrm{C}_{\mathrm{O}}
$$




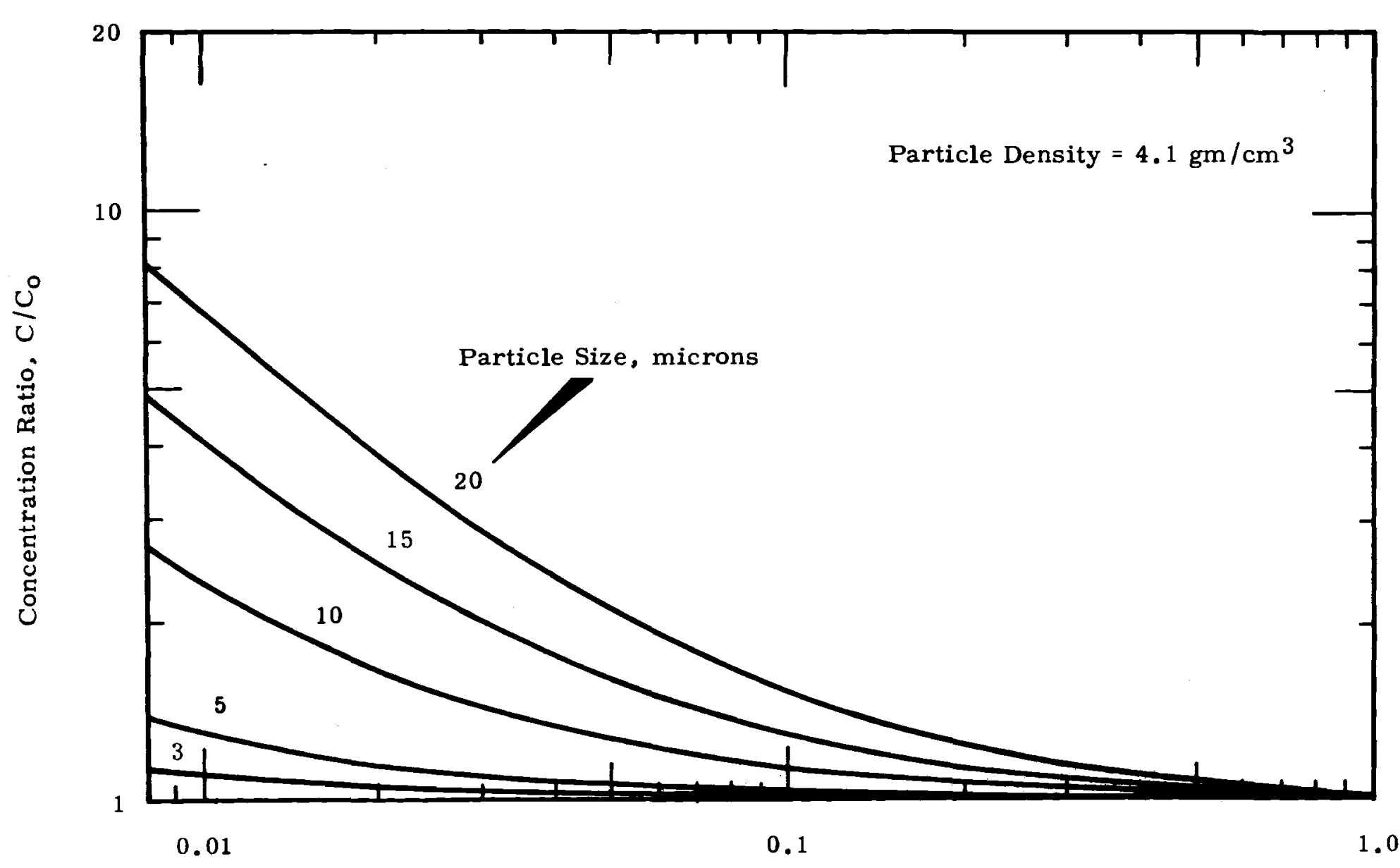

Sampling Ratio, $\mathrm{U} / \mathrm{U}_{\mathrm{O}}$

\section{FIGURE 19}

Concentration Ratios for a $2.7 \mathrm{mph}$ Windspeed 


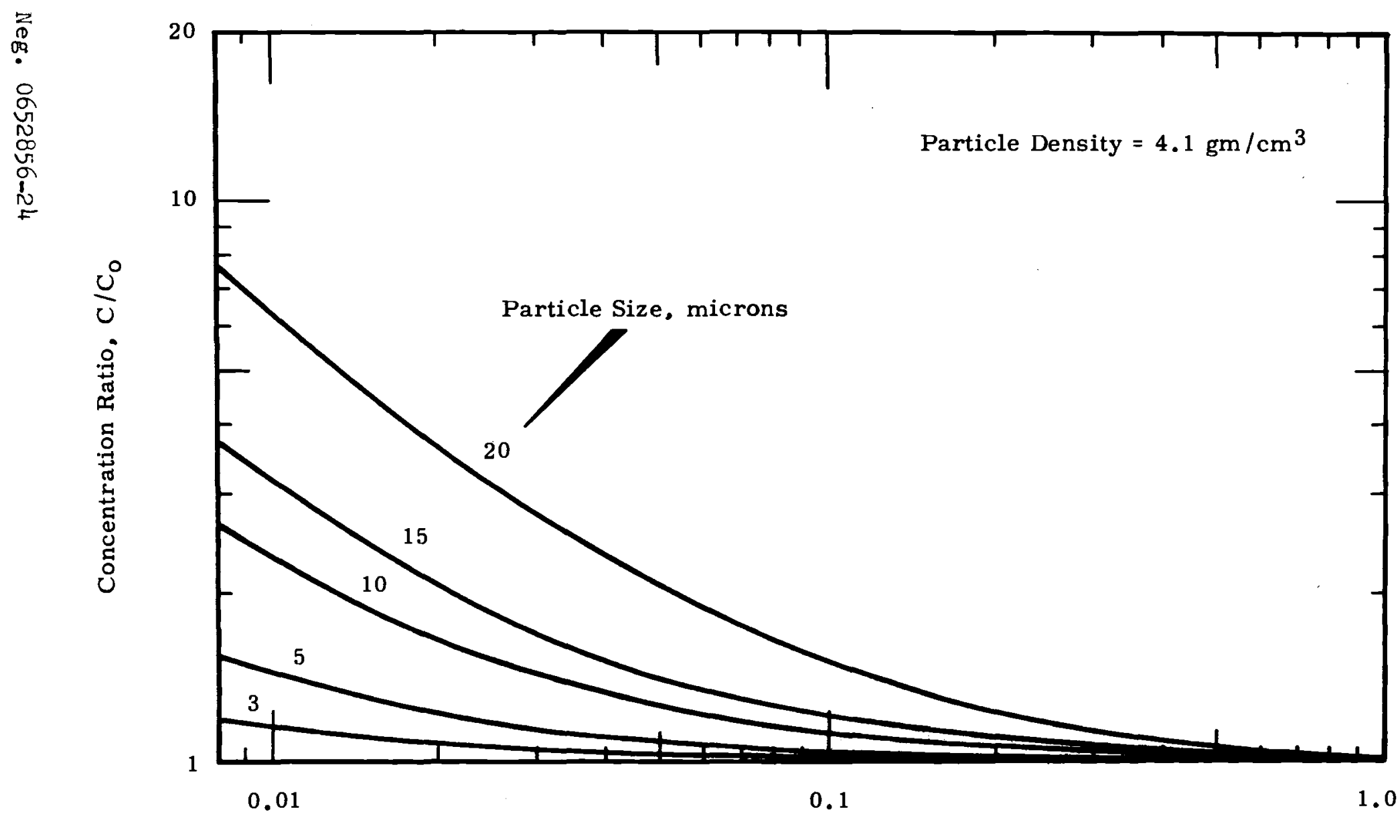

Sampling Ratio, U/Uo

\section{FIGURE 20}

Concentration Ratios for a $5.4 \mathrm{mph}$ Windspeed 


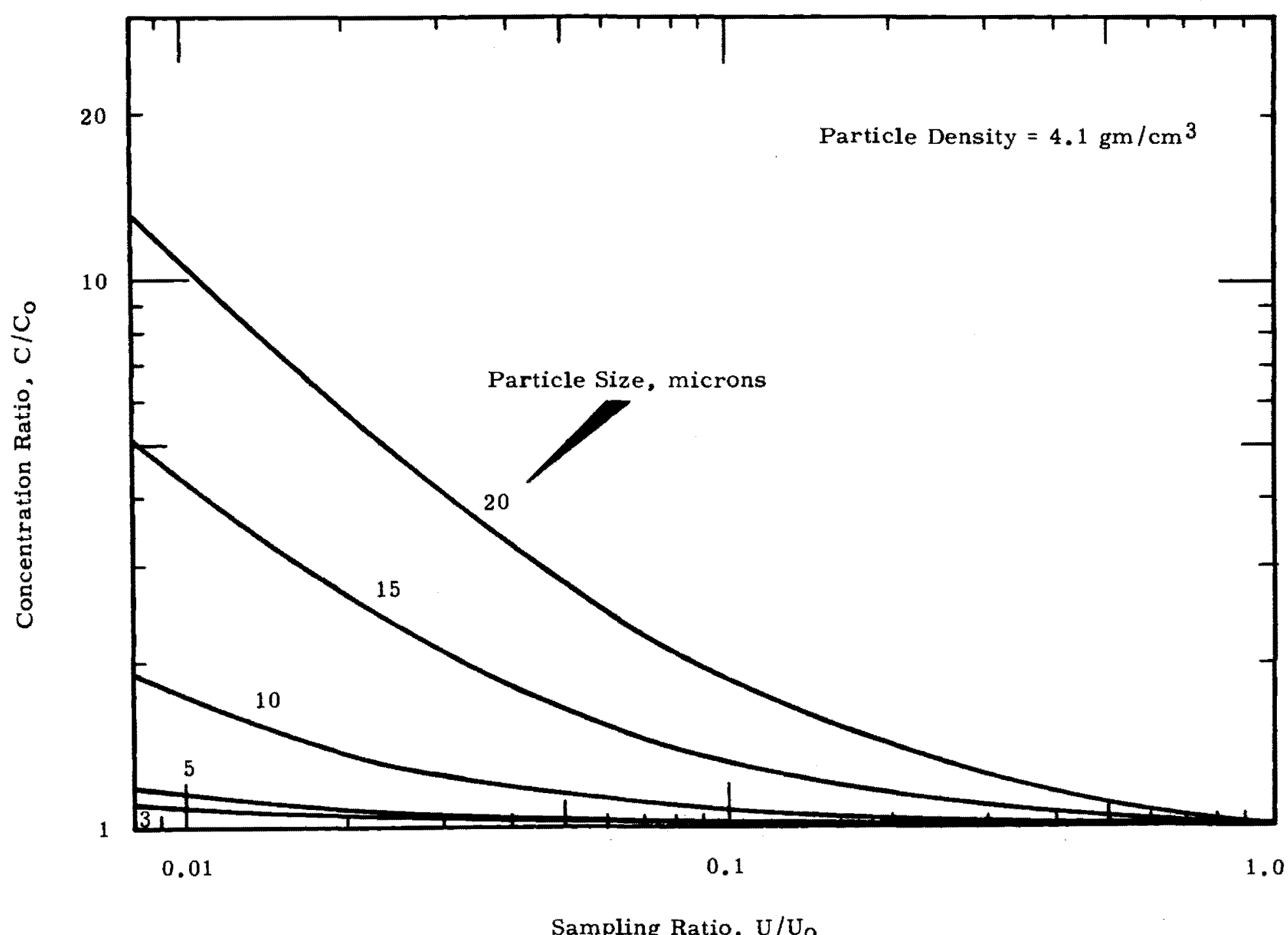

\section{FIGURE 21}

Concentration Ratios for a $9.0 \mathrm{mph}$ Windspeed 


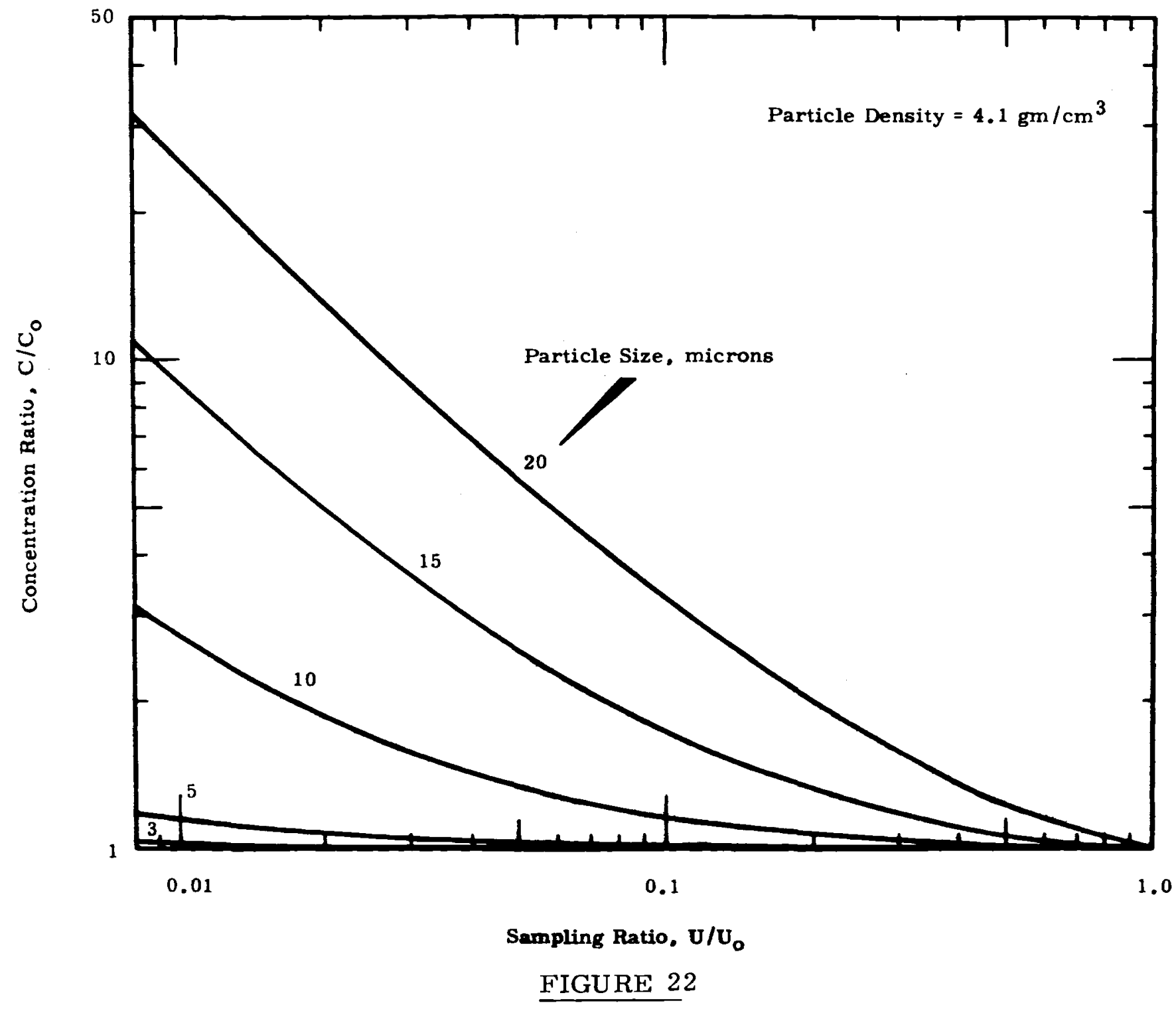

Concentration Ratios for a $16.5 \mathrm{mph}$ Windspeed 


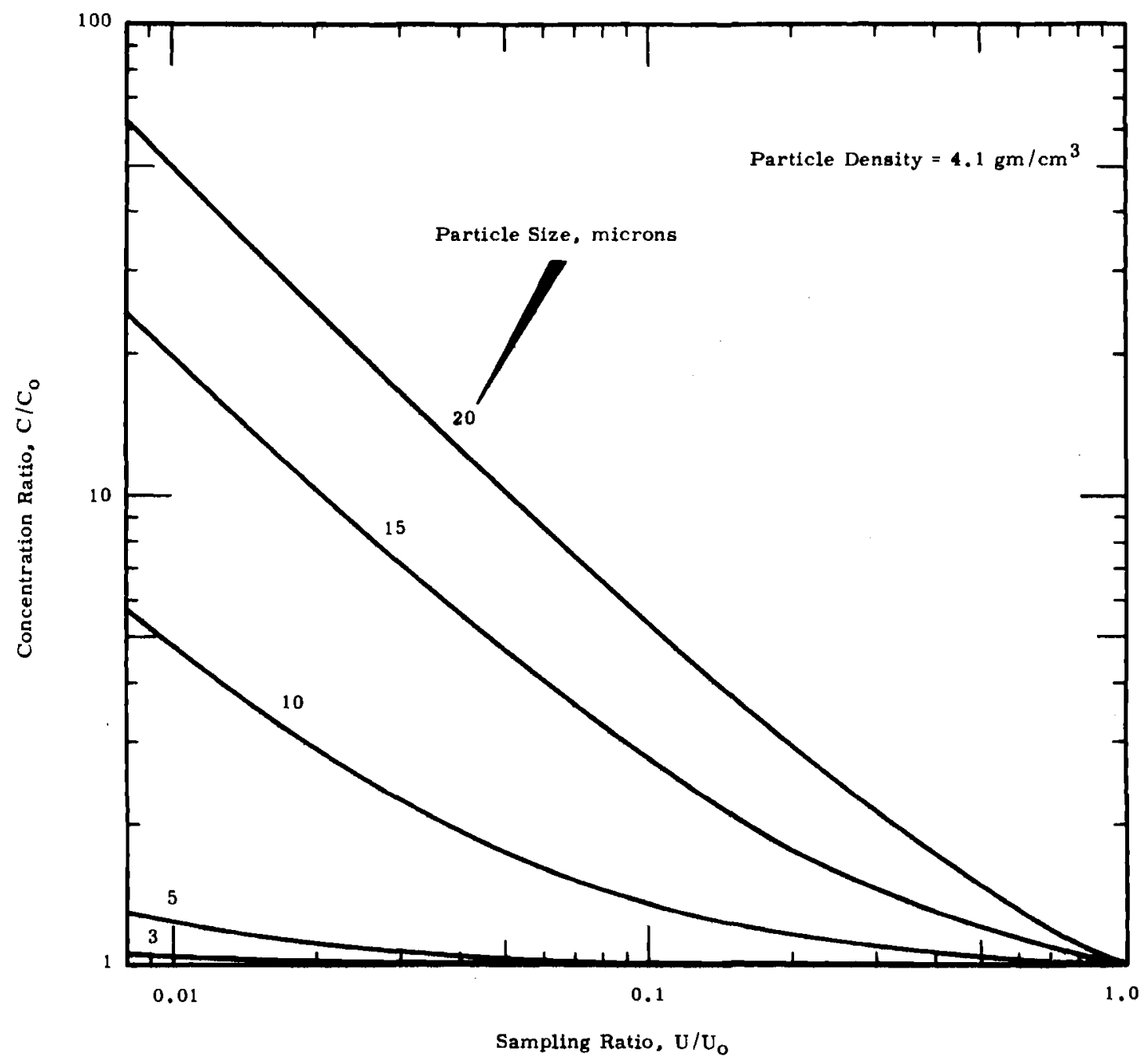

FIGURE 23

Concentration Ratios for a $30.0 \mathrm{mph}$ Windspeed 
for a 20 micron diameter particle at a sampling ratio of 0.01 for a $30 \mathrm{mph}$ windspeed.

In the practical case, the concentration ratios of interest are frequently the mass average concentration ratios for a particle size distribution. In comparison to the calculation of the concentration ratio, $c / C_{0}$, for each particle size in which the number of particles, $N$, is known, interpretation of the total mass collected on the subisokinetic filter requires a knowledge of the initial size distribution in the air. If this distribution and the total weight collected is known, the total mass concentration of particles in the air can be calculated. These calculations have been performed for the size distributions shown in Figure 5 , for type 2210, 2230 and a 45 weight per cent 2210 mixture of the two parent distributions. These distributions are representative of those used in atmospheric

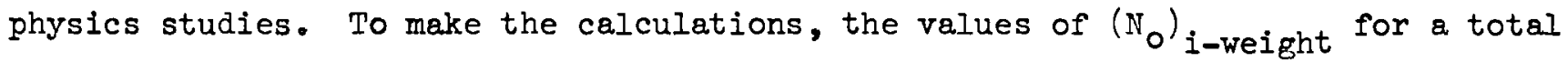
of $\mathrm{N}_{0}$ are calculated on a weight basis from the initial distribution curves for each particle size. Next, the values of $\left(N / N_{0}\right)_{i}$ are determined as previously for each particle size. These values are multiplied by the respective values, $\left(\mathbb{N}_{0}\right)_{i-w e i g h t}$, and the summation

$$
\mathrm{N}_{\text {weight }}=\sum_{i}\left(\frac{\mathrm{N}}{\mathrm{N}_{0}}\right)_{i} \quad\left(\mathrm{~N}_{0}\right)_{i \text { weight }}
$$

performed. Thus, the concentration ratios on a mass basis,

$$
\frac{\mathrm{C}}{\mathrm{C}_{0}}=\left(\frac{\mathrm{N}}{\mathrm{N}_{0}}\right)_{\text {weight }}\left(\frac{\mathrm{U}_{0}}{\mathrm{U}}\right)
$$

were determined for the size distributions and the results are shown in Figures 24 through 26 as a function of the sampling rates indicated by the dashed lines and the windspeeds indicated by the solid lines. As expected, these figures show that the concentration ratios are significant in value and that; (I) the concentration ratios increase as the average particle size increases, (2) the concentration ratios increase as the sampling rate decreases, and (3) the concentration ratios increase as the windspeed increases. As shown in Figure 26 for the distribution with the largest average particle size, the concentration ratios are much less than the limit for large particles. This limit is equal to the quotient $U_{0} / U$ since $N$ and $N_{0}$ are equal for large particles. 


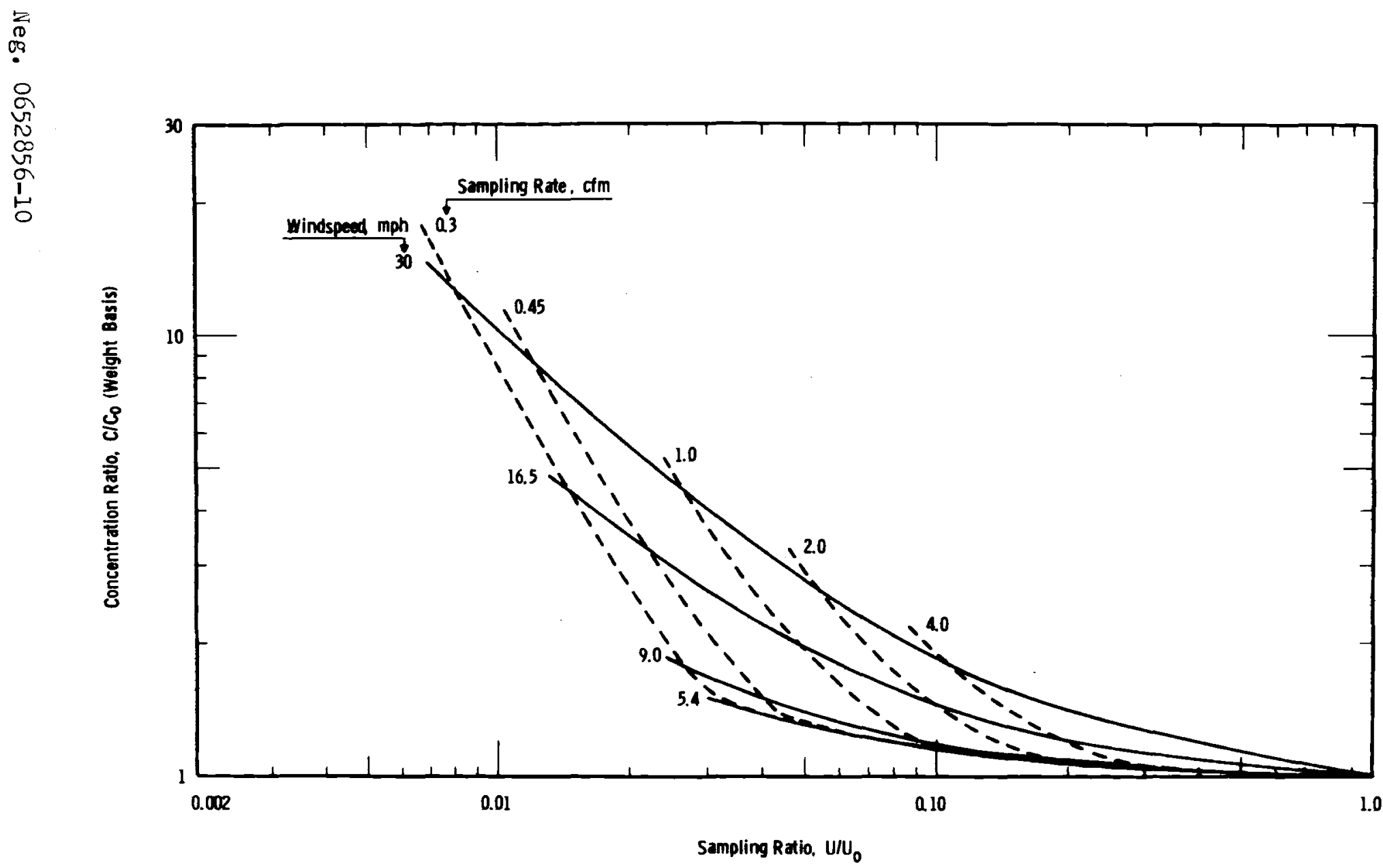

\section{FIGURE 24}

Concentration Ratios for Type 2210 Particles 


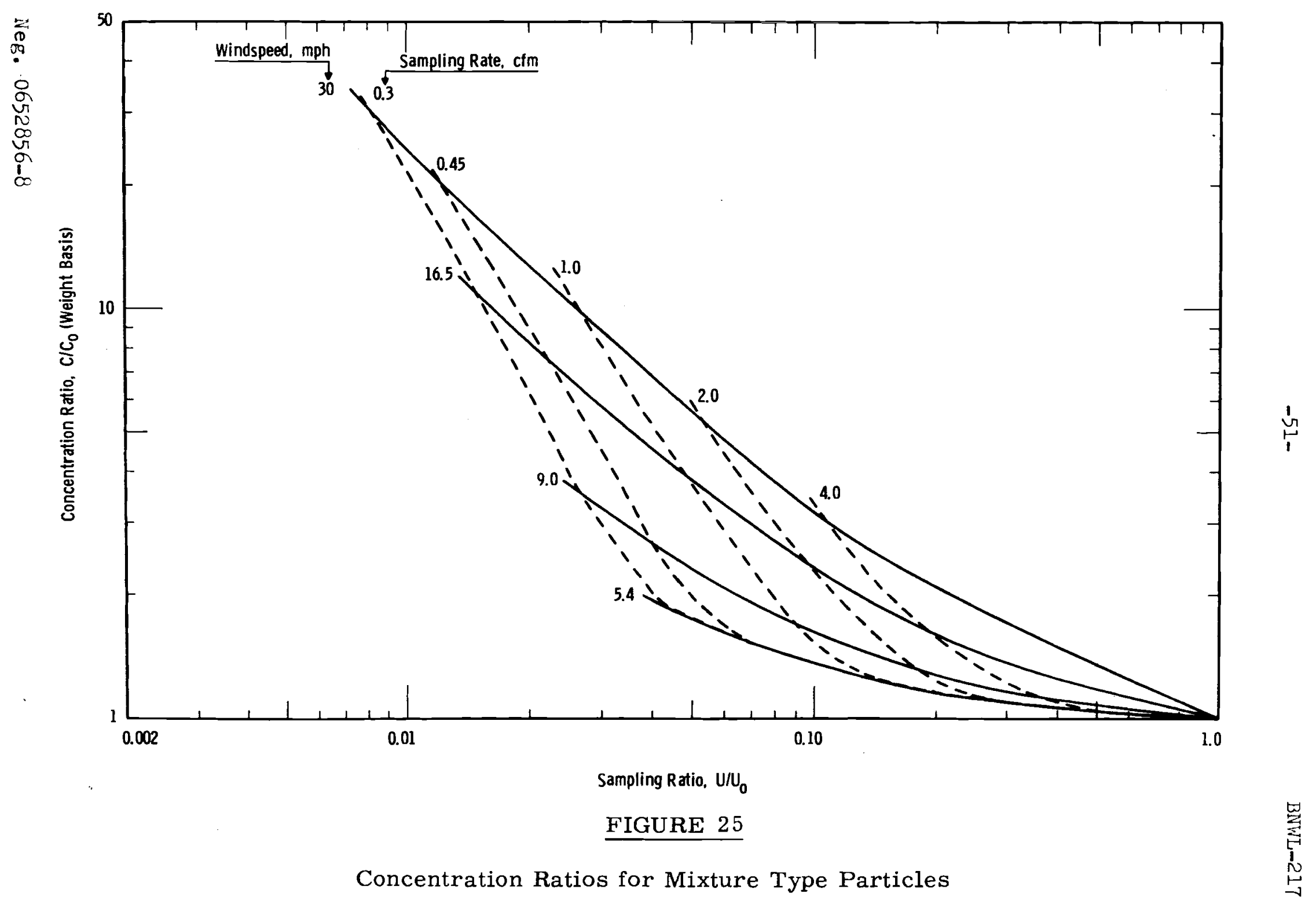


2
0
09
09
8
0
0
0
$心$
0
1
$\alpha$

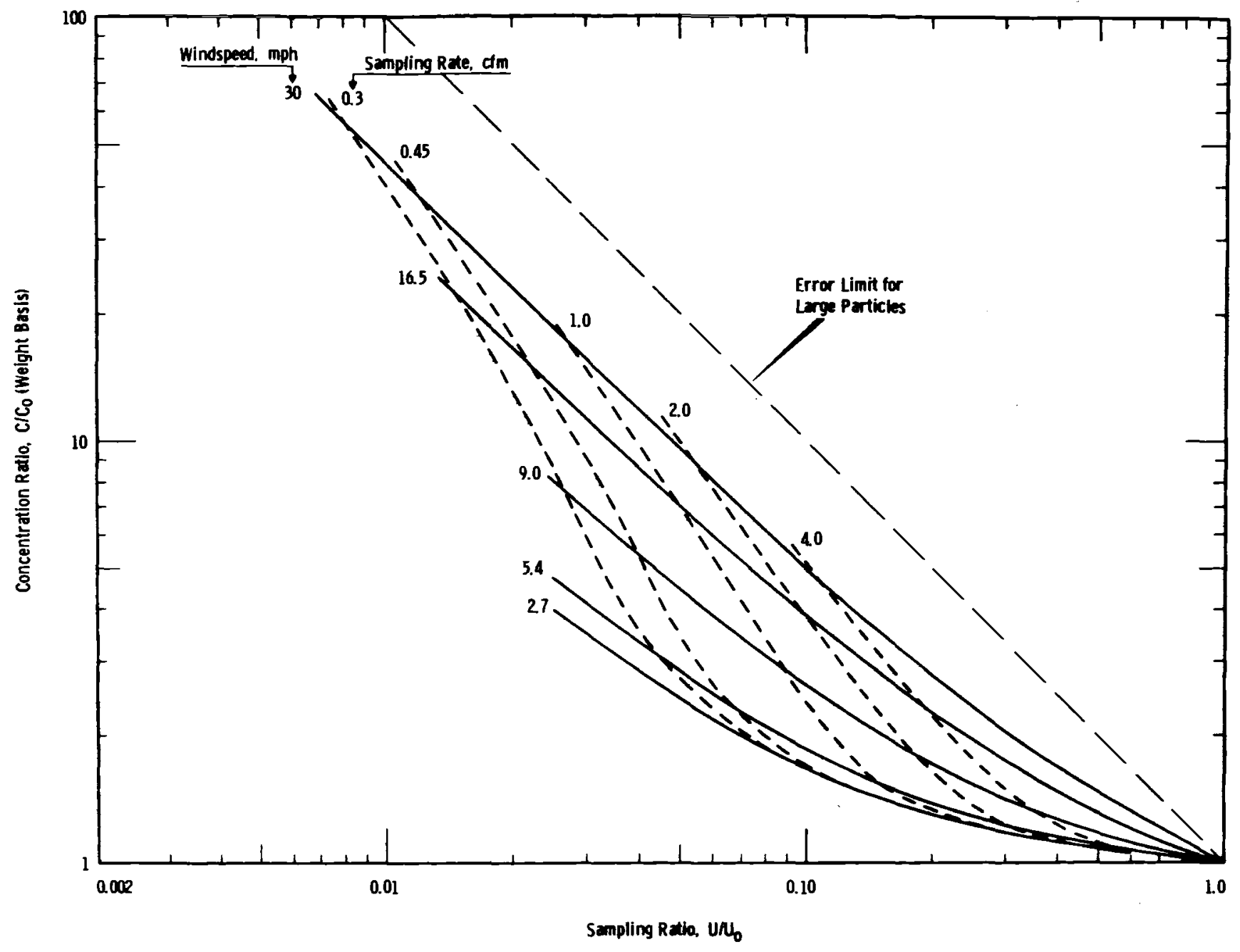

FIGURE 26

Concentration Ratios for Type 2330 Particles 
the mass of the material collected on a filter, $M$, is used to determine the mass average concentration of material in the air, $M_{0}$. That is

$$
M_{0}=\frac{M}{\left(U_{0} t\right)\left(C \cdot R_{0}\right)}
$$

where C.R. is the concentration ratio obtained from Figures 24 through 26. In conclusion, concentration ratio correction factors can be calculated for windspeeds and particle sizes of interest. However, these correction factors themselves are subject to considerable error. Improvement in the data could be achieved if a monodispersed aerosol were used. This would allow analysis of the entire filter. Even though the data could be improved, use of these sampling error concentration ratios should decrease the errors in estimating concentrations of zinc sulfide from subisokinetically obtained filters.

\section{ACKNOWLEDGEMENTS}

I wish to express my sincere appreciation to Lysle Schwendiman, Manager, Particulate \& Gaseous Waste Research, for designing the wind tunnel and for his thoughtful interest in the research; to Keith Thomas and to Ed Shdo for their hours of microscopic counting and sizing of particles. 
NOMENCLATURE

$C=$ particle concentration in air calculated from the subisokinetic sample, particles/volume

$C_{D}=$ drag coefficient

$\mathrm{C}_{0}=$ true air stream concentration, particles/volume

$\mathrm{d}=$ particle diameter

$f=$ particle size frequency distribution

$M=$ mass collected on subisokinetic filter.

$\mathrm{M}_{0}=$ average weight concentration of particles in air, welght/volume

$\mathbb{N}=$ number of each size particles collected on a subisokinetic sample

$N_{0}=$ number of each size particle collected on an isokinetic sample

Re $=$ particle Reynolds number, dup $g / \mu$

$R=$ filter radius, $20.5 \mathrm{~mm}$

$R e_{f}=$ filter Reynolds Number, $2 R v \rho_{g} / \mu$

$R e_{o}=$ initial particle Reynolds Number, $d u_{o} \rho_{g} / \mu$

$S=$ stop distance, Equation 6

$S_{S}=$ Stokes'stop distance, $\rho d^{2} u_{0} /(18 \mu)$

$S t_{k}=S_{s} / R$

$S t k_{D}=S / R$

$t=$ time or sampling time

$\mathrm{u}=$ particle velocity

$u_{0}=$ Initial particle velocity

$\mathrm{U}=$ subisokinetic sampling rate

$\mathrm{U}_{0}=$ isokinetic sompling rate

$\mathrm{v}=$ undisturbed air stream velocity

$\varepsilon=$ impaction efficiency from diverted air

$\mu=\operatorname{air}$ viscosity

$\rho_{p}=$ particle density

$\rho_{g}=\operatorname{air}$ density

$\phi=9 \operatorname{Re}_{f} \rho_{g} / \rho$ 
$-55-\quad$ BNWL-217

\section{REFERENCES}

[I] M.L。Barad, J.J. Fuquay. "The Green Glow Diffusion Program," Vol. I, HW-71400, January, 1962.

[2] RoJ . Engelmann. "Rain Scavenging of Particulates," HW-79382, December I, 1963.

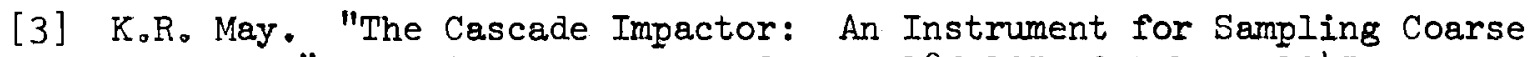
Aerosols," J.Sci. Inst., Vol. 22, pp 187-195, October, 1945.

[4] W. Sell. "Staubausscheidung an einfachen Korpen und in Luftfitern," Forsch. Gebiete Ingenieurw, Vol. 2, Forschungsheft, p. 347, August 1931.

[5] A.H. Yeomans, E.R. Rogers, W.H. Ball. "Deposition of Aerosol Particles," I. of Economic Entomology, Vol. 42, pp 591-596. 1949.

[6] W.C.L. Hemeon, C.F. Haines, Jr. "The Magnitude of Errors in Stack Dust Sampling," Air Repair, Vol. 4, No. 3, pp 159-164.

[7] S. Badzioch. "Collection of Gas-borne Dust Particles by Means of an Aspirated Sampling Nozzle," Brit. J. Appl. Phys., Vol. 10, pp 26-32 (1959).

[8] H.H. Watson. "Errors Due to Anisokinetic Sampling of Aerosols," Ind. Hyg. Quat., Vol. 15, pp 21-25, March, 1954.

[9] Vo Vitols. "Theoretical Limits of Errors Due to Anisokinetic Sampling of Particulate Matter," Department of Industrial Health, University of Michigan, Ann Arbor, Michigan (Paper 65-85 presented at the 58th Annual Meeting of the Air Pollution Control Association, June 20-24, 1965, Toronto, Canada).

[10] R.A. Duffee, E.J. Schulz, E.W. Ungar. Unpublished data. Battelle Memorial Institute, 1960. ("Disturbing Factors in Particulate Sampling," presented at the Third Conference on Applied Meteorology, Santa Barbara, Calif. April 5-8, 1960).

[11] NoR. Fuchs. "The Mechanics of Aerosols," translation edited by C.N. Davies, The McMillian Company, New York, New York, 1964.

[12] C.J. Stairmand. "The Sampling of Dust-Laden Gases," Trans. Inst. Chem. Engrs. (British), Vol. 29, pp 15-20, 1951.

[13] J.D.Wilcox. "Isokinetic Flow and Sampling," J. Air Pollution Control Assoc., Vol。 5, pp 226-245, February, 1956.

[14] R.W. Wasser. "Sampling Effluent Gases for Particulate Matter," Amer. Indus. Hygiene Assoc。. J., Vol. 19, pp 469-476, December, 1958.

[15] A.B. Whiteley, L.N. Reed. "The effect of Probe Shape on the Accuracy of Sampling Flue Gases for Dust Control," J. Inst. Fuel. Vol. 32, pp 316-320, 1959。

[16] C.N。 Davies. "Recent Advances in Aerosol Research," The McMillian Company, New York, New York, p 142, 1964.

[17] H。L。Green, W.R. Lane. "Particulate Clouds: Dusts, Smokes, and Mists", D. Van Nostrand Co., Inc., Princeton, New Jersey, 1964, 2nd Edition, pp 271-275. 
[18] PoG。Wo Hawksley, S. Badzioch, JoH. Blackett. "Measurement of Solids in Flue Gases," The British Coal Utilization Research Assoc., Leatherhead, Surrey, England, 1961.

[19] E.A. Anderson. "On the Quantitative Determination of Industrial Gas Dispersoids," Trans. Am。Inst. Ch. E., Vol. 34, pp 589-601, 1938.

[20] S. Badzioch. "Correction for Anisokinetic Sampling of Gasborne Dust Particles," J. of Inst. Fuel., Vol. 33, pp 106-110, 1960.

[21] WoE. Caldwell. "Characteristics of Large Hell Gate Direct-Fired Boiler Units," Trans. Am. Soc. Mech. Eng., Vol. 56, pp 73-75, 1934.

[22] W. Farhenback. "Die Dynamik des Staubes und ihr Einfluss auf die Staubgehaltmessungen," Forschung auf dem Gebiets des Ingenieurwessen, Vol. 2, pp 395-407, 1931.

[23] J.H. Griffiths, T.D. Jones, Trans. Inst. Mining, Eng., Vol. 22, p 150, 1940.

[24] P.H. Hardie. "Fuel Panel Discussion on Cinder Catchers," Trans. Am. Soc. Mech。Eng., Vol. 59, pp 355-358, 1937.

[25] E. Zimmerman. "Messung von Flug Staub in Rauchgasen," Zietschrift des Vereines Deutscher Ingenieure, Vol. 75 , paper FSP-56-2, pp 73-75, 1934 .

[26] H॰F. Kraemer, H.F. Johnstone. "Collection of Aerosol Particles in Presence of Electrostatic Fields," Ind. Eng. Chem., Vol. 47, pp 2426-2434, 1955.

[27] C.J. Stairmand. "Dust Collection by Impingement and Diffusion," Trans. Inst.

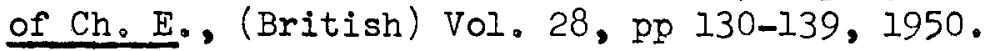

[28] C.E。 Lapple, C.B. Shepard. "Calculation of Particle Trajectories," Ind. Eng. Chem., No. 5, Vol. 32, pp 605-617, 1951.

[29] V.G.Levich。 "Physiochemical Hydrodynamics," Prentis Hall, Inc., Englewood Cliffs, New Jersey, pp 221-230, 1962.

[30] WoE。 Rans. "The Impaction of Aerosol Particles on Cylindrical and Spherical Collectors," Engineering Experiment Station Technical Report No. 3, University of Illinois, March, 1951.

[31] W.F. Rans. "Princioles of Inertial Impaction," Engineering Research Bulletin 66, Penn. State University, 1956.

[32] W.E。Ranz, J.B. Wong. "Impaction of Dust and Smoke Particles," Ind. Eng. Chem., Vol. 44, pp 1371-1381, 1952.

[33] J.W.Wong, S.E. Ranz, H.F. Johnstone. "Inertial Impaction of Aerosol Particles on Cylinders," J. of App. Physics, Vol. 26, pp 244-249, 1955.

[34] R.J.Brun, W. Lewis, P.J. Perkins, J.S. Serafini. "Impingement of Cloud Droplets on a Cylinder and Procedure for Measuring Liquid-Water Content and Droplet Sizes in Supercooled Clouds by Rotating Multicylinder Methods," NSA-1215, p. 5, National Advisory Committee for Aeronautics, 1955.

[35] M.0. Rankin. Zinc Sulfide Particle Detector, HW-55917, May 1958. 
[36] R.T. Doyle. Unpublished data, Hastings-Raydist Inc,, Hampton, Virginia (personal communication, Director of Instrument Sales, August 23, 1965).

[37] H.L. Green and W.R. Lane. "Particulate Clouds: Dusts, Smokes, and Mists," D. Van Nostrand Co., Inc., Princeton, New Jersey, pp 229-232, 1964.

[38] R.M. Mugele and H.P. Evans. "Droplet Size Distributions in Sprays," Ind. Eng. Chem., Vol. 43, No. 6, pp 1317-1324, June, 1951.

[39] J.H.K. Kao. "A Graphical Estimation of Mixed Weibull Parameters in Life Testing of Electron Tubes," Technometrics, Vol. 1, No. 4, pp 389-407, November, 1959.

[40] G.A. Sehmel. "Analysis of Particle Size Frequency Distributions," Hanford Radiological Sclences Research \& Development Annual Report for 1964, BNWL-36. 


\section{APPENDIX A}

PARTICLE COLLECTION ON NOZZLE WALL

Brass nozzles were fitted around the filter retaining ring in order to obtain isokinetic samples at windspeeds of $5.4 \mathrm{mph}$ and greater. The inlet of the nozzles were smaller than the filter and thus the flow limitations across the membrane filters (0.8-micron pore size) would not limit the range of experimental wind velocities. Two types of nozzles were used and these are shown schematically in Figure 27 as well as in the photograph of Figure 9. The nozzle exit diameter was 1.59 inches and the internal diameter of the nominal 4l-mm retaining ring was 1.61 -inches.

In general particle deposition on the internal walls of the nozzle was a function of the flow rate through the nozzle. By looking at the walls under ultra-violet illumination the patterns could be seen. At low flow rates gravity was most important and particles fell and deposited on the lower half of the nozzle. At higher flow rates turbulence became more important and particles appeared to be uniformly distributed throughout the nozzle.

To determine the particle collection on the nozzle walls, the filter paper used during isokinetic sampling was replaced and air drawn through the filter as the particles were removed from the walls with a small air jet. The particles collected on the filter were those initially on the nozzle as well as on the retaining ring. The particles collected around the filter circumference and few particles were collected in the middle regions of the filter. After the particles were counted and sized, the results were combined with those determined for the filter used during isokinetic sampling. Thus, the fraction deposited on the nozzle walls of those entering the nozzle was determined.

The fractional collection on the nozzle walls is shown in Figure 27 as a function of the upper limit of each size range in which the particles were sized. The collection is a marked function of particle size and shows up to 70 per cent collection on the walls for the larger particles. These data indicate that in the use of nozzle for obtaining isokinetic samples the collection on a nozzle as well as on the filter must be considered. 

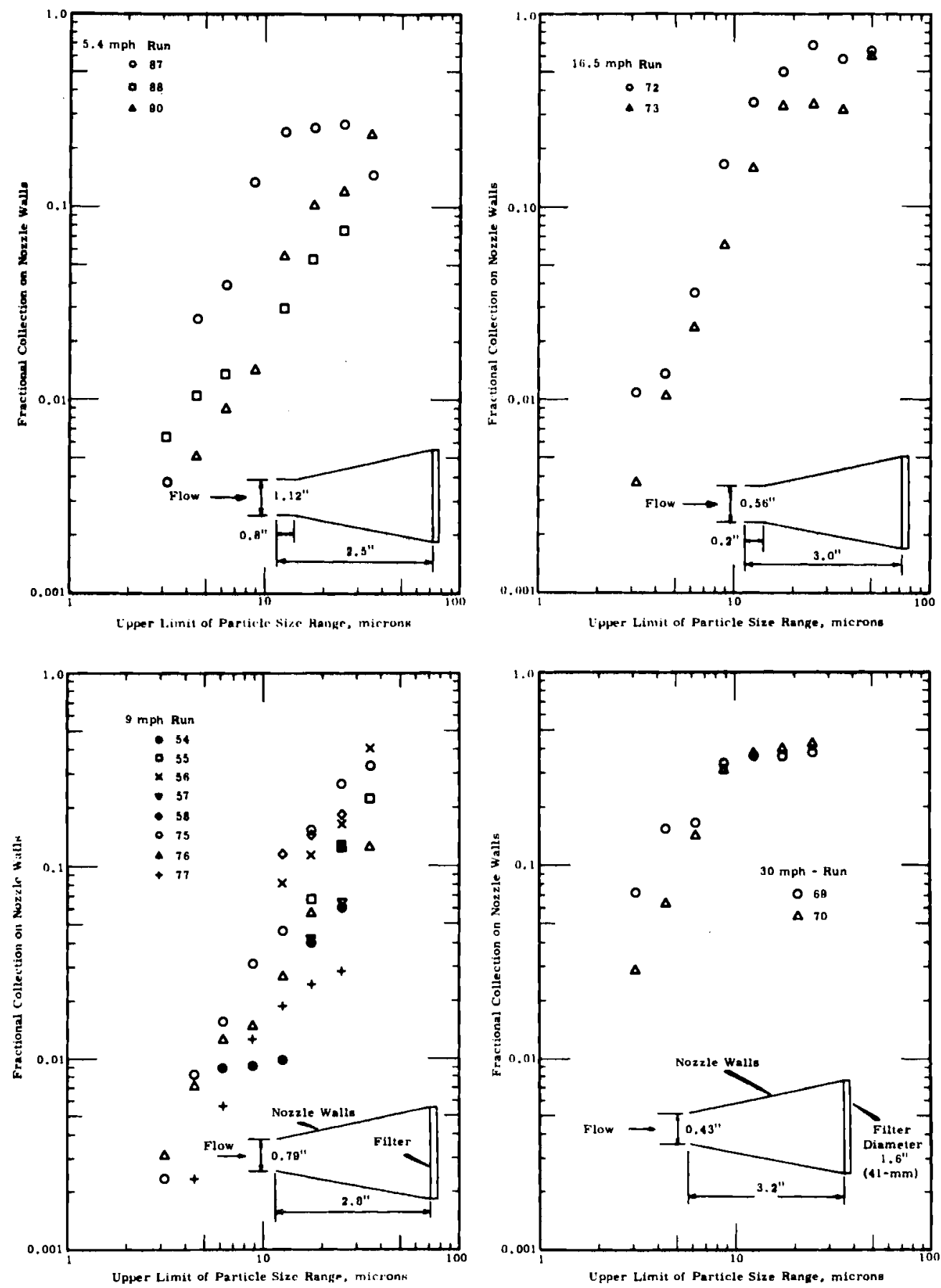

\section{FIGURE 27}

Collection of Particles on Nozzles at Isokinetic Entrance Velocities

Neg. 0653405-1 


\section{APPENDIX B}

PREVIOUSLY REPORTED DATA

Collection ratios from an early initial experiment for flow at $3.7 \mathrm{mph}$ were reported in a communication to $R$. J. Fngelmann and used by him in a study on particle washout by rain drops ${ }^{[2]}$. The same experimental data interpreted by the methods described in this report lead to significantly different collection ratios than those earlier reported, particularly for particles $4 \mu$ and smaller. The difference resulted from two causes. The first is that the computer method of determining the size distribution curve described in this report was more precise than the visual curve fitting method initially employed. The second cause for the difference was the use of the model later developed which requires that greater weight be given the impaction efficiency measurement of the no-flow filters than to the direct experimental determination of the collection ratios for various subisokinetic flows. As shown in the report, the model used with the impaction efficiency measurement makes interpretation of the results more consistent, even though significant disparities are evident between experimentally determined $\mathbb{N} / \mathbb{N}_{0}$ and that shown by the model.

In the $3.7 \mathrm{mph}$ run an anomalously high collection ratio was determined for four and five $\mu$ and smaller particles. These unusually high values must be discounted, but even so, for all particle sizes the experimental points fall consistently above the curve given by the model as shown in Figure 28 . These differences are not resolved and further detailed studies are indicated. 


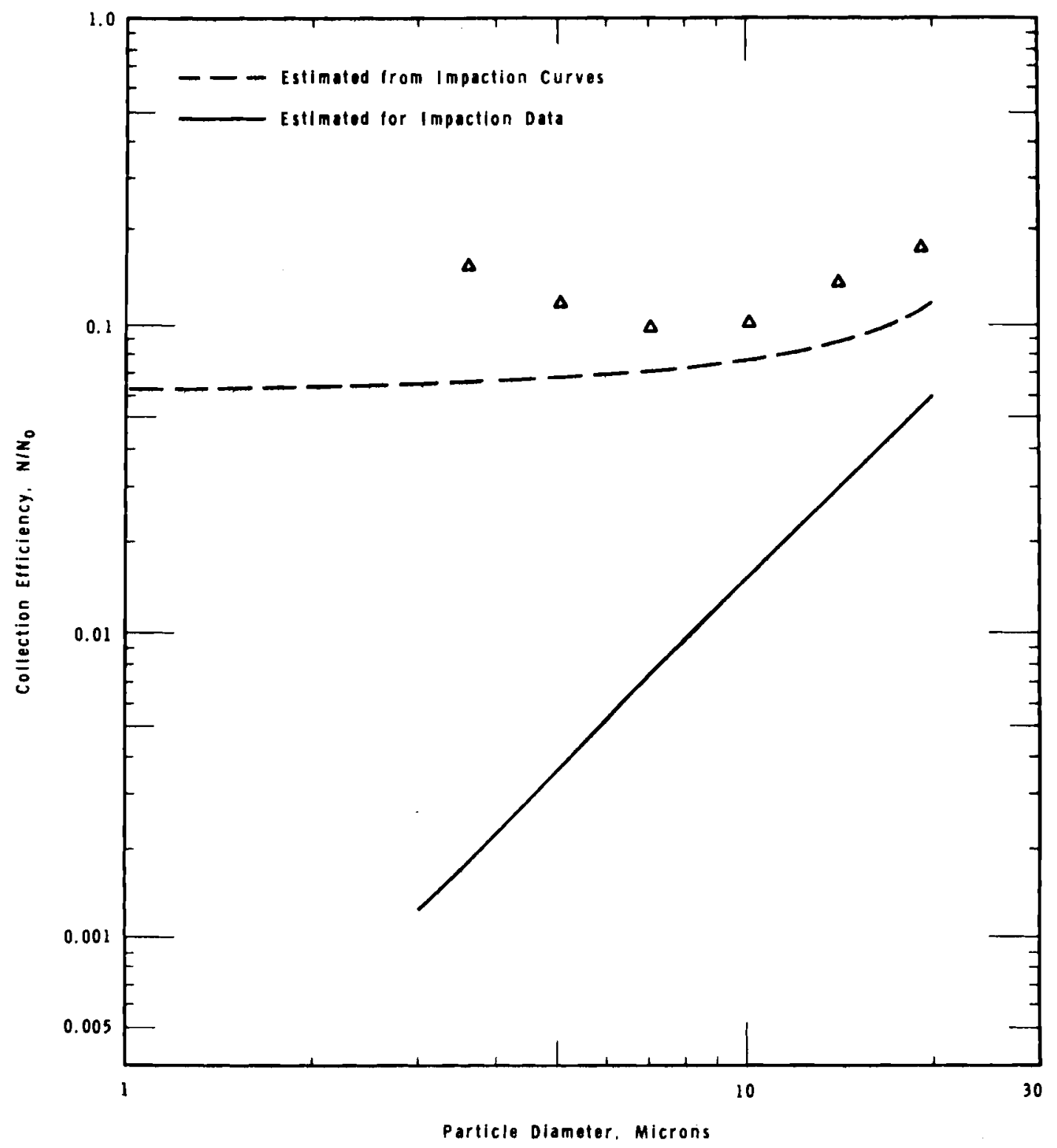

FIGURE 28

Collection Ratio for each Particle Size as a Function of Sampling Ratio $\left(\mathrm{U} / \mathrm{U}_{\mathrm{o}}\right)$ for a $3.7 \mathrm{mph}$ Windspeed

Neg. 0652856-2 


\section{DISTRIBUTION}

On-Site Distribution

Copy No.

Pacific Northwest Laboratory

1.

2.

3.

4.

5.

6.

7.

8.

9.

10.

11.

12.

13.

14.

15.

16.

17.

18.

19.

$20 .-77$.

78.

79.

WJ Bair

JR Bovington

WE Davies

WL Dotson

CE Elderkin

RJ Engelmann

$\mathrm{RF}$ Foster

JJ Fuquay

DI Hagen

WT Hines

ER Irish

RL Junkins

$\mathrm{KH}$ Larson

PW Nickola

RS Paul

RW Perkins

EH Phinney

IC Roberts

LC Schwendiman

GA Sehmel

CL Simpson

BD Stuart

80.

Technical Information Files

81.

Technical Publications

Douglas-United Nuclear

82.

ML Smith

Hanford Occupational Health Operation

83.

FE Adley

Richland Operations Office

84.

Technical Information Library

85.

RK Sharp 
DISTRIBUTION (Continued)

Special External Distribution

\begin{tabular}{cl}
$\begin{array}{c}\text { Number of } \\
\text { Copies }\end{array}$ & \\
\hline 5 & Division of Technical Information Extension \\
1 & W.A. Cote, Dept, of Health, Education and Welfare \\
Robert A. Taft Sanitary Engineering Center \\
4676 Columbia Parkway, Cincinnati, Ohio 45226
\end{tabular}

